\title{
Review-Organic-Inorganic Hybrid Functional Materials: An Integrated Platform for Applied Technologies
}

\author{
Sajjad Husain Mir, ${ }^{1,2, z}$ Larry Akio Nagahara, ${ }^{3, *}$ Thomas Thundat, ${ }^{4, *}$ \\ Parvaneh Mokarian-Tabari, ${ }^{2}$ Hidemitsu Furukawa, ${ }^{5, *}$ and Ajit Khosla $\oplus^{5, *, z}$ \\ ${ }^{I}$ Department of Materials System Science, Graduate School of Nanobioscience, Yokohama City University, \\ Kanazawa-ku, Yokohama 236-0012, Japan \\ ${ }^{2}$ Advanced Materials and BioEngineering Research Centre (AMBER) \& CRANN, Trinity College Dublin, The \\ University of Dublin, Dublin 2, Ireland \\ ${ }^{3}$ Department of Chemical and Biomolecular Engineering, Whiting School of Engineering, Johns Hopkins University, \\ Baltimore, Maryland 21218, USA \\ ${ }^{4}$ Chemical and Biological Engineering, University of Buffalo, New York 14260, USA \\ ${ }^{5}$ Department of Mechanical System Science, Graduate School of Science and Engineering, Yamagata University, \\ Yonezawa, Yamagata 992-8510, Japan
}

\begin{abstract}
Hybrid functional materials, constituting both inorganic and organic components, are considered potential platforms for applications in extremely diverse fields such as optics, micro-electronics, transportation, health, energy, energy storage, diagnosis, housing, environment and the highly relevant area is Internet of Things (IoT). Material properties of hybrid materials can be tuned by modification of the composition on the molecular scale to produce smart materials. Cross-cutting approaches, to synergistically couple molecular engineering and processing allows to tailor complex hybrid systems of various shapes with perfect control over size, composition, functionality, and morphology. The detailed description and discussion of variety of hybrid functional organicinorganic materials and their contribution in the designing of specific modern technologies is the prime focus of this review.

(C) The Author(s) 2018. Published by ECS. This is an open access article distributed under the terms of the Creative Commons Attribution 4.0 License (CC BY, http://creativecommons.org/licenses/by/4.0/), which permits unrestricted reuse of the work in any medium, provided the original work is properly cited. [DOI: 10.1149/2.0191808jes]

(cc) BY
\end{abstract}

Manuscript submitted January 31, 2018; revised manuscript received April 20, 2018. Published May 4, 2018. This paper is part of the JES Focus Issue on Ubiquitous Sensors and Systems for IoT.

There is an enormous demand for hybrid materials to provide technological breakthroughs with the most sought after being the enabling of the IoT. Interest in the field of IoT will witness exponential growth over the next decade as markets realize the true potential of realtime data acquisition for various entertainment, knowledge dissemination, defense, environmental, and healthcare applications. Many of the well-established materials, such as metals, ${ }^{1}$ ceramics, ${ }^{2-4}$ or plastics ${ }^{5,6}$ cannot fulfill all technological desires for the various new applications. In addition to the early interest in structural hybrid materials based on carbon-silicon networks, many recent efforts have centered on the design of functional hybrid materials which harness the chemical activity of their components. This approach has been successfully used in recent years in the design of hybrid polymers ${ }^{7}$ with special emphasis on structural hybrid materials based on mixed silicon-carbon networks prepared by sol-gel methods ${ }^{8-12}$ which can also entrap additional active species. ${ }^{13}$ In this field the stakes are high and scientists aim at producing structural materials with properties between those of inorganic glasses and organic polymers. ${ }^{8}$ But the expectations go beyond mechanical strength and thermal and chemical stability. These new materials are also sought for improved optical, ${ }^{14-17}$ and electrical ${ }^{18,19}$ properties, luminescence, ${ }^{12,20-25}$ ionic conductivity, ${ }^{26-28}$ and selectivity, ${ }^{29-32}$ as well as chemical ${ }^{33-35}$ or biochemical ${ }^{36-38}$ activity. Chemical activity is of core importance in functional materials. Sensors, selective membranes, all sorts of electrochemical devices, from actuators to batteries or supercapacitors, supported catalysts or photoelectrochemical energy conversion cells are some important devices based on hybrid functional materials.

Hybridization is a multifaceted strategy. In some cases, conducting organic polymers act just as a solid polymeric support for active species, whereas in other hybrid systems the activity of organic and inorganic species combines to reinforce or modify each other. But in every case the work on these hybrid materials involves the underlying use and sometimes even the explicit search for synergy. Hybrid

*Electrochemical Society Member.

${ }^{\text {zE} E-m a i l: m i r s h @ t c d . i e ; ~ k h o s l a @ y z . y a m a g a t a-u . a c . j p ~}$ organic-inorganic materials in general represent the natural interface between two worlds of chemistry each with very significant contributions to the field of materials science, and each with characteristic properties that result in distinct advantages and limitations. Research in the topic of hybrid materials has challenges and opportunities. The main challenge is managing to synthesize hybrid materials that keep or enhance the best properties of each of the components while reducing their particular limitations. Undertaking this challenge provides an opportunity for developing new materials with synergic behavior leading to improved performance or to new useful properties. Indeed, hybrid materials frequently involve a combination of components that have been thoroughly studied in their respective fields but provide an additional dimension to their properties in becoming part of the hybrid compound.

Hybrid materials can demonstrate better properties compared with their individual counterparts, where in inorganic material can play several roles: enhancing the mechanical and thermal stability, modulating the refractive index, providing an accessible and interconnected porous network for sensing or catalysts, or contributing specific magnetic, electronic, redox, electrochemical or chemical properties. Organic components greatly extend the range of matrices available to synthetic chemists. Organic materials can offer opportunities to modify mechanical properties enabling the production of films and fibers, to obtain by simple casting various geometric structures for integrated optics, to control the porosity and connectivity of networks, and to adjust the balance hydrophilic/hydrophobic character. Organic components can also contribute a specific physical or chemical property including electrical or optical characteristics, electrochemical behavior, chemical or biochemical reactivity, etc.

In the last decades hybrid materials were developed on a large scale with a lot of realized economic applications. The increase in the publications and patent applications from the 2005 until the year 2016 is tremendous as shown in Fig. 1. Due to the possibility of designing properties through the hybridization of the organic and inorganic components, multifunctional materials ${ }^{39,40}$ can be created. Such materials can easily be casted into thin films, which could be used for modification of cheaper materials by a simple surface 


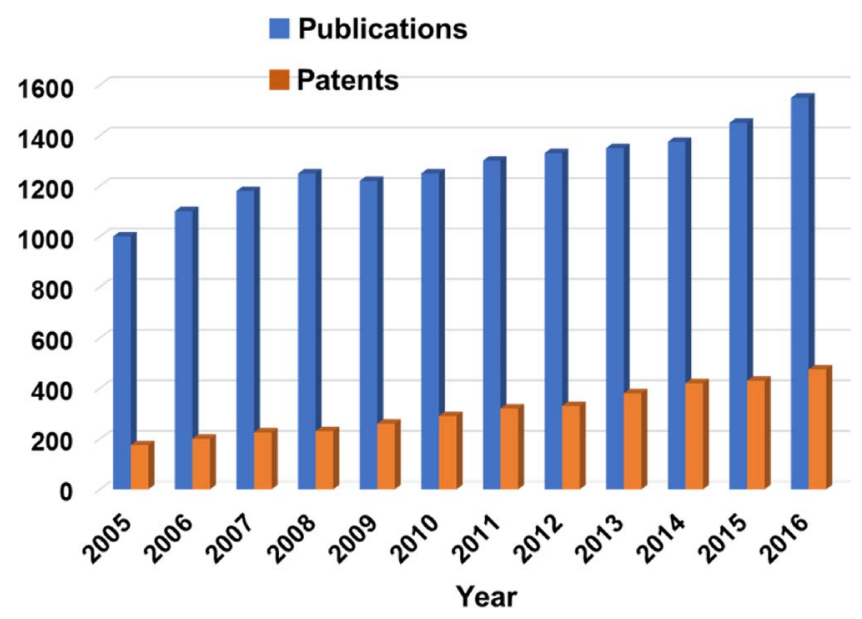

Figure 1. Number of papers published in last decade on hybrid materials. (Source: SciFinder Scholar: https://scifinder-n.cas.org).

treatment, e.g., scratch resistant coatings. ${ }^{41-43}$ Based on the molecular or nanoscale dimensions of the building blocks, light scattering in homogeneous material can be avoided and optically transparent nanocomposite materials suitable for optical applications can be produced. ${ }^{44-47}$ In some cases phase separation of organic and inorganic components is used for the formation of porous materials. ${ }^{48,49}$ Smart materials can be fabricated by modification of the composition on the molecular scale. For example, electroactive materials, ${ }^{50,51}$ electrochromic materials, ${ }^{52-54}$ sensors,${ }^{55-57}$ membranes,${ }^{58,59}$ and biohybrid materials. ${ }^{60-62}$ This review will center on organic-inorganic hybrid materials and their utilization as optical and electronic functional materials for development of new technologies. Mostly, we will focus on organic-inoragnic hybrid materials containing polymers as one of the component, which has brodned the scope of hybrid materials for diverse areas of applications. ${ }^{63-71}$

\section{Categorization of Functional Hybrid Materials}

Functional hybrid materials are not just a physical mixture. They are nanocomposites at the molecular scale, having at a minimum one component, either the organic or the inorganic constituting part, with a characteristic length on the nanometer size (a few $\AA$ to several tens of nanometers). ${ }^{72}$ The sum of the all properties of the hybrid materials are not the outcome of properties individual contributions of their components, but also from the strong synergy created by a hybrid interface. ${ }^{73,74}$ The nature of the inorganic/organic interface, including the types of interactions present, the surface energy, and the existence of labile bonds plays a strong role in controlling of a number of properties (electrical, optical, mechanical, separation capacity, catalysis, sensing capability, and chemical and thermal stability). Owing to their large importance, various functional hybrid materials can be categorized into two main families depending on the nature of the interface combining the organic components and inorganic materials. ${ }^{72}$ Class I deals with hybrid systems where the organic and inorganic parts interact by weak bonds including Van der Waals, electrostatic or hydrogen bonds. Class II indicates hybrid materials in which these components are linked by covalent or ionic-covalent chemical bonds. Indeed, various hybrid materials consist of both types of interfaces, strong and weak, but due to the significance of the presence of strong chemical bonds on the final hybrid material properties, these types of hybrid are grouped into class II. The compounds of hybrid class I present a number of interesting features such as ease of synthesis of the material, the avoidance of heterofunctional metal-organic precursors, and, when desired, the facile removal of the organic phase to easily create functional architectures by self-assembly. However, currently we are witnessing the increasing development of hybrid materials of class II. The existence of covalent chemical bonds between organic and mineral components presents a number of advantages: i) the potential to synthesis entirely new materials from functionalized alkoxides, ii) minimization of phase separation, and iii) better definition of the organic-inorganic interface. Such defined control can lead to a better understanding of the material and the relationship between microstructure and properties, an easier adjustment of the hydrophilichydrophobic balance, etc. Effective grafting of organic functionality to the inorganic network avoids a drawback of the hybrid compounds of Class I. That is the potential departure of organic components while the material is in use, e.g. in applications like sensors or catalysts.

Synthetic methodologies for hybrid materials.-Irrespective of type of hybrid interface there are numerous synthetic strategies and processes present for the fabrication and formation of hybrid materials. ${ }^{74-77}$ The fundamental synthetic strategies are illustrated schematically in Fig. 2. The reaction route (path A, Fig. 2) represents sol-gel as well as hydro- and solvothermal synthesis, where molecular precursors such as alkoxides, metal salts in the presence of complexing polyfunctional precursors, and organofunctional precursors are used. In this case organic functionality is a non-labile terminal or bridging organic, R'. Sol-gel (path A1, Fig. 2) involving hydrolysis and condensation reactions from alcoxyorganosilanes or alcoxyorganostannanes $\left(\mathrm{R}^{\prime} \mathrm{Si}(\mathrm{OR})_{3}, \mathrm{R}^{\prime}-\mathrm{Sn}(\mathrm{OR})_{3}\right.$ where $\mathrm{R}^{\prime}$ is an organic functionality) of alkoxides or metal halides $\left(\mathrm{M}^{\prime}(\mathrm{OR})_{n}, \mathrm{MX}_{n}\right.$ with $\mathrm{M}=\mathrm{Ti}, \mathrm{Zr}, \mathrm{Nb}, \mathrm{Al}$ etc.) and mixtures thereof. However, these materials are generally amorphous with polydispersed size distributions, and this complexity makes it difficult to study their structureproperties relationships. Path B (Fig. 2) illustrates strategies based on the assembly of preformed monodispersed nano-objects. ${ }^{7477-79}$ These nano-objects can be clusters or nanoparticles (metal oxides, metals and alloys, chalcogenides), nanoparticle composite type core/shell, or nano-sheets of lamellar compounds (clays, double hydroxides, phosphates, oxides and lamellar chalcogenides). These nano-objects, in their various compositions, must be stable under the chemical conditions imposed during assembly. Therefore, they are very often pre-or post-hybridized by attaching organic components to their surface in order to provide greater stability and transferability in the assembly environment (aqueous or non-aqueous solvents, within polymers, etc.). These nano objects can be surface functionalized with polymerizable ligands, spacers, organic molecules or telechelic polymers, functional dendrimers, biomolecules, etc. The use of preformed hybrid objects opens the way for "legochemistry" which allows the building of custom materials or hybrid assemblies. This modular approach from nano objects presents a number of advantages. The step-by-step development of the material allows better control of its structure on the semilocal scale. Prefabricated nano-objects often show reduced reactivity compared to that of molecular precursors; the inorganic component is relatively monodispersed on the nanometer scale allowing the development of more well-defined structures that facilitate characterization and control over the quality of the final material.

Path C exploits the self-assembly properties of amphiphilic molecules and polymers to generate supramolecular templates to control the texture and morphology of the growing solid or gel phase. ${ }^{74,75,79,80}$ These inorganic or hybrids phases can be generated from precursors previously described in paths A and B (molecular clusters, nanoparticles, etc.). Two approaches are currently being explored: i) using preorganized organic, biological, or inorganic templates, akin to structural molds for casting the material and ii) synergistic assembly where the precursors and texturing agents (templates) are co-assembled in situ into organized architectures. ${ }^{81,82}$ Path C is particularly interesting because it allows the construction of a continuous ensemble of nanocomposites from ordered dispersions of inorganic nano-objects in an organic matrix to the controlled nano-segregation of organic polymers in inorganic matrices. A striking example is that of hybrid mesostructured phases from which mesoporous solid minerals or hybrids can be generated. Recently, this approach, combined with the use of hexafunctional organosilanes, has yielded a new class of hybrid mesoporous solids. These materials made from bridged silesquioxanes in presence of surfactants exhibit a high degree of 
Bottom-up strategies from Molecular Precursors

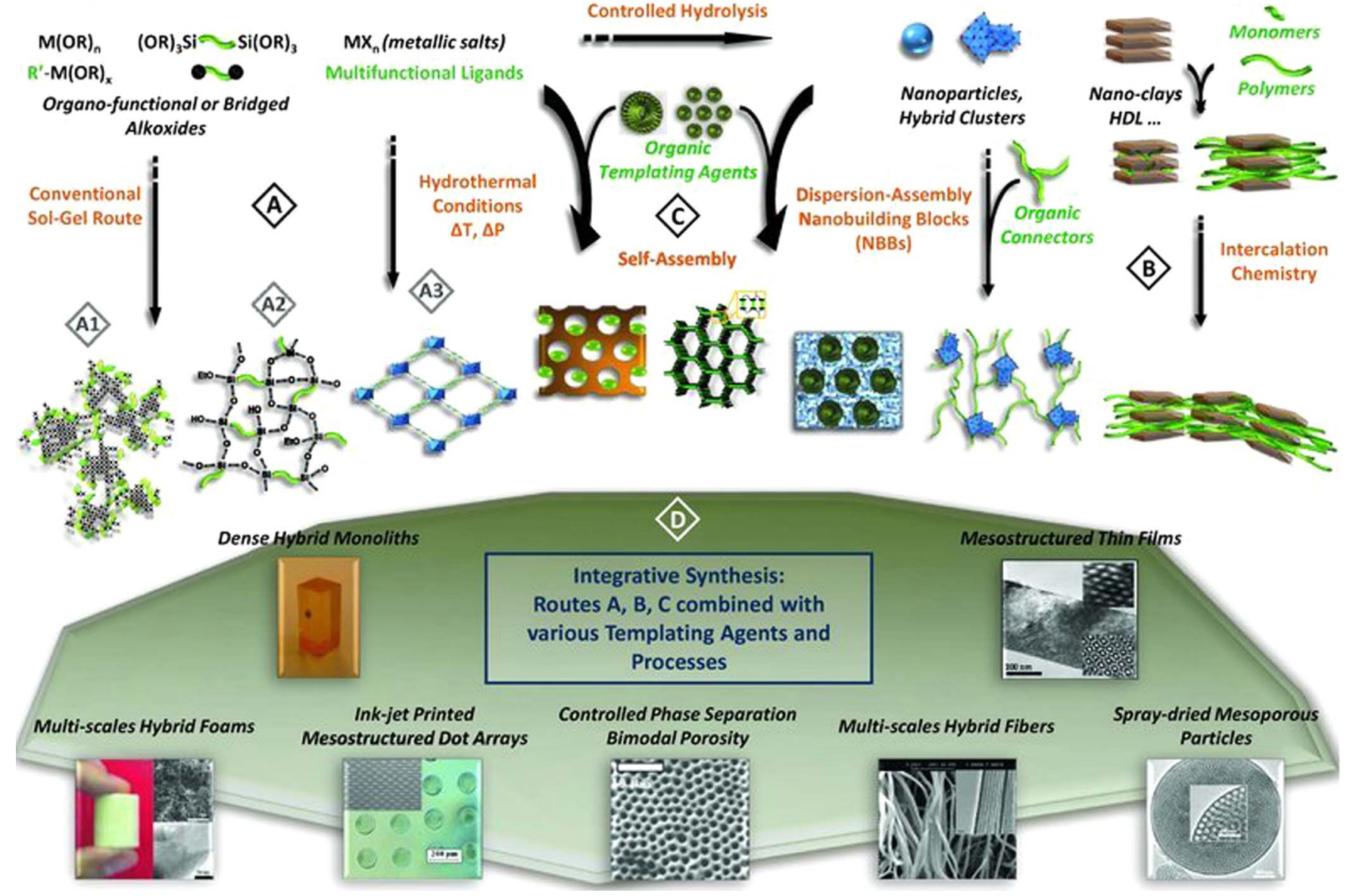

Figure 2. Synthetic Methadologies of hybrid functional materials (Reproduced with permission from Ref. 79, copyright 2010, Wiley).

organization and porosity accessible to a secondary functionalization via post grafting. ${ }^{81}$

Path D is an integrative approach in which the chemical arsenal described above can be combined with templates of variable size (organo-gelifiers, bacteria, latex beads, submicron colloidal minerals) and the physical chemistry of soft matter. This is described mainly in the context of production processes (nano-molding and multiple replications, reactive extrusion, electrospinning). It also may involve morpho-synthesis, which involves chemical transformations in confined geometries: micro-emulsions, micelles, vesicles, etc., phase separation kinetically controlled by the gelification of the network (spinodal), the use of breath figures, or Rayleigh-Besnard instabilities, dissipatives structures, etc, as templating modes and texturation of materials induced by external stimuli (mechanical and optical, electric or magnetic fields, etc.) generated during their formation process. ${ }^{75,79,83,84}$ These strategies in a single stage can generate hybrid materials with hierarchical structure. This structural hierarchy is one essential characteristic of biological materials, where topological and structural organization is present at all scales, from the nano or supramolecular, to the micro and often millimeter scale. These hierarchical structures observed in vivo present not only great complexity but also a high selectivity to external stimuli. Natural materials can serve as models to inspire and develop new concepts and new "biomimetic strategies" in materials engineering. Learning the skills of some living systems and transcribing the rules and methodology of their construction should enable us to develop new materials, with superior performance characteristics. ${ }^{79,85,86}$
Hybrid nanocomposite materials, synthesized from colloidal nanometer-sized particles of metals or metallic compounds dispersed in polymers has attracted great attention. ${ }^{87}$ In these materials, inorganic nanoparticles (NPs) are not the host for the intercalation of organic polymers, but at the same time they are too large to be considered guest species conforming to the structure of the polymers. These materials could therefore be considered as true composite materials where each component still retains its own structure but with an increased interfacial interaction derived from the small particle size. Within this category a first group of materials is formed by nanosized metal particles dispersed in polymers. ${ }^{88-92}$ Most frequently the metals used are precious metals, $\mathrm{Pd}$ and $\mathrm{Pt}$, and the hybrids are designed for catalytic purposes, such as proton and oxygen reduction, ${ }^{88,93,94}$ hydrogen oxidation ${ }^{88}$ as well as hydrogenation reactions. ${ }^{89}$ A second group of materials is constituted by those in which the nanodispersed phase is an oxide. Several hybrid materials based on colloidal particles of transition metal oxides $\left(\mathrm{g}-\mathrm{Fe}_{2} \mathrm{O}_{3},{ }^{95,96} \mathrm{MnO}_{2},{ }^{97,98} \mathrm{CuO},{ }^{99} \mathrm{TiO}_{2},{ }^{100-102}\right.$ and $\left.\mathrm{WO}_{3}{ }^{103,104}\right)$ as well as tin oxide ${ }^{105}$ and silica ${ }^{105,106}$ have been reported. In addition to the more extensively studied work on oxides, recent reports have extended this family of hybrid composites to other colloidal semiconducting particles such as CdS, ${ }^{107,108} \mathrm{CdSe},{ }^{106-108}$ and copper or silver halides. ${ }^{107}$

Nanoparticles (NPs), in the 1-100 nm sizes tend to bridge the gap between small molecules and bulk materials. ${ }^{109}$ As a class of materials, NPs offer a variety of opportunities to investigate the evolution of material properties with particle dimensions. Metal NPs, especially $\mathrm{Au}, \mathrm{Ag}$ and $\mathrm{Cu}$ NPs, have been extensively investigated over 

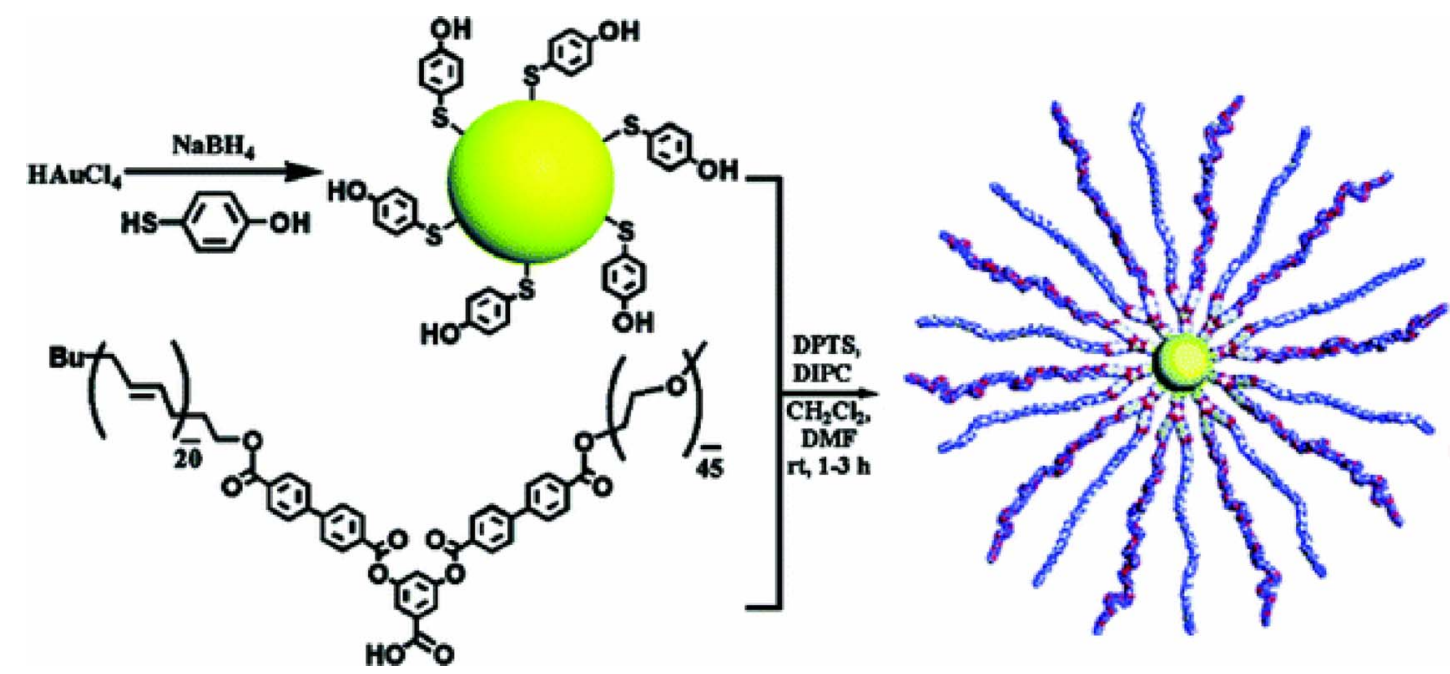

Figure 3. Fabrication of amphiphilic Au(PB-PEG) ${ }_{n}$ nanoparticles. (Reproduced with permission from Ref. 117, copyright 2006, American Chemical Society).

the past decade due to their unique electronic, optical and catalytic properties. ${ }^{110,111}$ These properties are neither those of bulk metal nor those of molecular compounds as has been widely demonstrated in both experimental and theoretical investigations, but they strongly depend on the particle size, shape and interparticle distance as well as the nature of the protecting organic shell. ${ }^{112}$ The chemical stability of NPs is crucial to avoid degradation processes such as partial oxidation or undesired sintering of particles. The lack of sufficient stability of many NPs has impeded the development of real world applications of these nanomaterials.

The use of polymeric stabilizers for metal NPs has inspired the studies of various synthetic routes to link polymers to metal particles and the investigations on properties as well as potential applications of the hybrid materials. The advantages of using polymers as stabilizers are not only for the enhancement of long-term stability, adjustment of the solubility and amphiphilicity of NPs. They also include the functionalization of NPs with polymers to achieve higher and tunable surface-density of shell/brush, to tailor properties of NPs, as well as to promote compatibility and processibility. For example, to assemble AuNP films with ordered structures, Genson et al. ${ }^{113}$ and Zubarev et al. ${ }^{114}$ prepared AuNPs functionalized with amphiphilic polybutadiene-poly(ethylene glycol) (PB-PEG) V-shaped arms by esterification of PB-PEG chains to mercaptophenol-stabilized AuNPs (Fig. 3). Approximately $65 \mathrm{~V}$-shaped molecules were tethered to a pre-formed AuNP, resulting in a high grafting density of $0.2 \mathrm{~nm}^{2}$ per V-shaped molecule. This value reaches the limits of the dense packing of phenylbenzoate groups in the upright orientation. These amphiphilic AuNPs formed stable Langmuir monolayers at the air/water and the air/solid interfaces. At these interfaces, the binary polymer arms vertically segregated into a dense polymer corona. These corona-surrounded the AuNPs, preventing their large-scale agglomeration keeping individual nanoparticles well-separated from each other and forming flattened, pancake nanostructures. Composite materials with ordered structures consisting of conducting polymers and metal nanoparticles are of great interest and promising for further applications in micro- and optoelectronics. Intelmann et al. ${ }^{115}$ prepared AuNPs on ultrathin films of polythiophene and polythiophene derivatives. The ultrathin films of polythiophene derivatives bearing hydroxyl groups were esterified with thioctic acid that contained a dithiolane moiety. The dithiolane moiety was utilized to immobilize AuNPs from a monodisperse gold sol synthesized by citrate reduction. The immobilized AuNPs were not removed by Scotch tape tests, indicative of the successful adhesion of AuNPs on the films of polythiophene derivatives through a covalent bond formed between the dithiolane moiety and gold. Cho and Park ${ }^{116}$ reported the spontaneous deposition of $\mathrm{Au}$ and $\mathrm{Ag}$ NPs on sulfur containing conducting polymer surfaces of poly(3-methylthiophene) (P3MeT) and poly(3,4ethylenedioxythiophene) (PEDOT) by simply dipping the polymer films into colloid solutions containing these particles. The currentvoltage curves indicated that the contacts between the particles and the polymer surfaces were ohmic, indicating potential applications in electrocatalysis for fuel cells as well as for electronic devices. Polymer-protected AuNPs were also prepared by encapsulating preformed colloidal AuNPs with water-soluble conductive poly(aniline2-carboxylic acid) by Englebienne and Hoonacker ${ }^{117}$ The composite nanoparticles displayed significant enhancements in photonic performance, and offers new opportunities for biosensing applications.

Recently, our group has reported a facile networked alignment of AgNPs, attained and stabilized by employing a graft copolymer bearing $\mathrm{C}=\mathrm{S}$ moieties (Fig. 4). AgNPs in the complex were in uniform and nanosized. The cavity of the network of Ag complex manifested the translucency. The vertical conductivity under compression suggests potential applications for printable electronic devices such as touch screens. The high conductivity under strong compression is ascribable to the reduced insulation by the compression of the softer polymer chains.

Mir et al. ${ }^{18}$ has reported a facile one-pot approach for preparing hierarchical nanowire-networks of hollow polymer@Pd nanospheres. The nanospheres were hierarchically assembled into the nanowirenetwork upon drying. The Pd nanowire-network served as an active catalyst for Mizoroki-Heck and Suzuki-Miyaura coupling reactions with a trace amout of $500 \mu \mathrm{mol} \%$ Pd was sufficient for quantitative reactions, due to the presence of highly active sites originating from high-index facets, kinks, and coalesced structures (Fig. 5). The polymer@Pd nanosphere also served as a printable conductive ink for a translucent grid pattern with excellent horizontal conductivity $\left(7.5 \times 10^{5} \mathrm{~S} \mathrm{~m}^{-1}\right)$.

Metal nanostructures may have useful effects on the photoluminescence of nearby emitters. It has been found that chromophores situated in the vicinity of isolated colloidal metal particles in suspension usually experience quenching of their fluorescence, ${ }^{118,119}$ Schneider and Decher ${ }^{119}$ fabricated metal core-polymer shell capsules by use of layer-by-layer (LBL) deposition of oppositely charged polyelectrolytes onto 13-nm-diameter AuNPs, where nonfluorescent polyelectrolytes are spacer layers and fluorescent organic dyes are situated in the outer polymer layer (Fig. 6).

\section{Technology Driven Exploration of Hybrid Materials}

Hybrids materials for Opto-electronic devices.-Depending on the type of connection between the inorganic and polymeric components, nanocomposites can be classified into two categories: one 

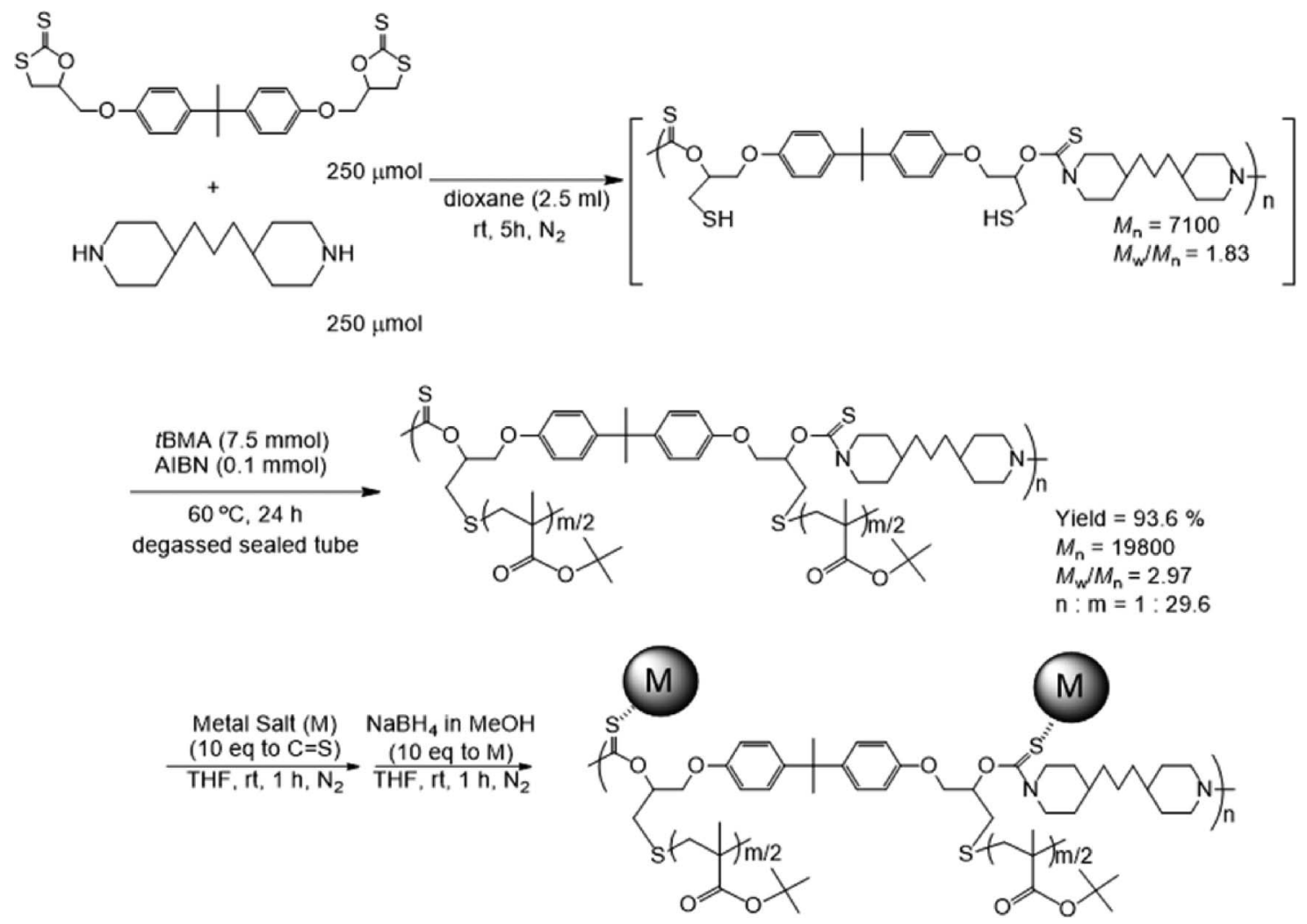

Figure 4. Graft copolymer, polyTU-g-PtBMA-AgNP complex, (reproduced with permission from Ref. 19a, copyright 2017, Springer).

in which the inorganic material (nanocrystals, colloids, polyoxometalates) is embedded in a polymeric matrix, ${ }^{120}$ and the other where the organic polymer is confined into an inorganic template. ${ }^{121}$ In the first case, inorganic-in-organic composites, the good processability
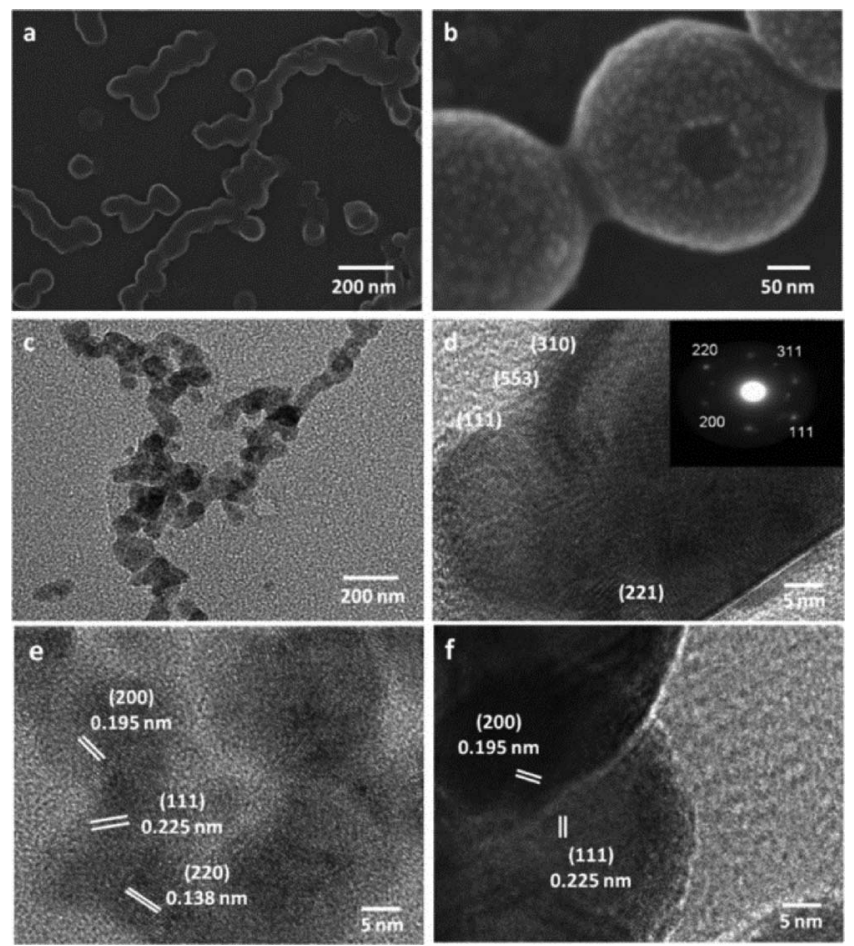

Figure 5. SEM (a,b), TEM (c), HRTEM (d-f), and selected area electron diffraction (SAED) pattern (inset in d) images of the Pd nanowire-network. (Reproduced with permission from Ref. 18, Wiley). and low density of the polymer component, in combination with the high mechanical durability and well-defined optoelectronic properties of the inorganic component, are harnessed. This allows the combinations of the advantages of the rapidly developing field in optoelectronic technology ${ }^{122}$ with attractive properties of semiconductor nanocrystals (NCs). Optical properties of this class of lumophores are determined by the quantum confinement effect, so that their emission color and the electron affinity can be finely controlled, not only by the material choice, but also by size within a single synthetic route. ${ }^{123,124}$ Proper surface passivation leads to improved chemical stability and

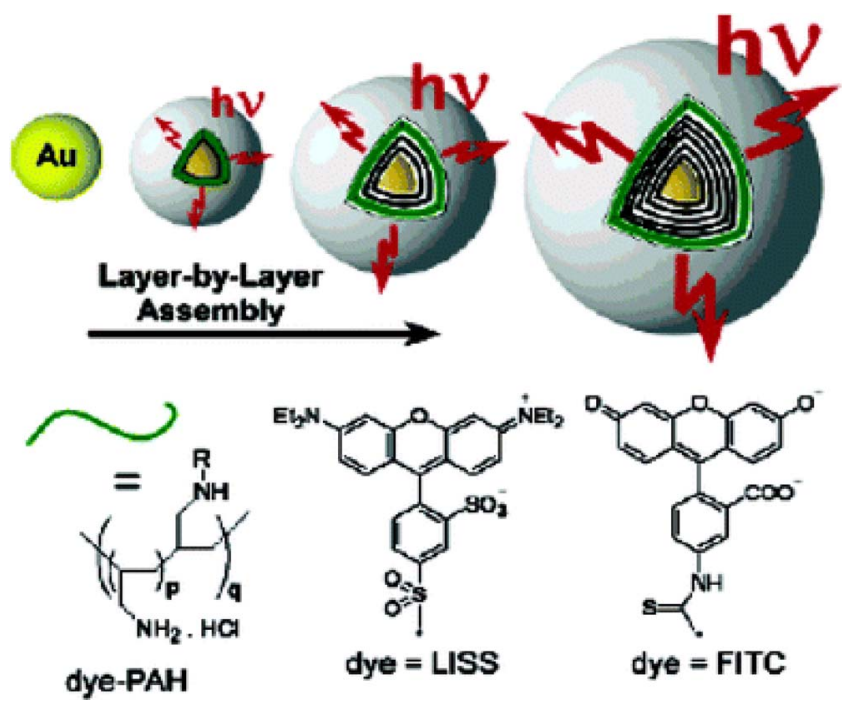

Figure 6. Layer-by-layer assembly for the construction of core-shell nanoparticles containing fluorescent corona layers. (Reproduced with permission from Ref. 119, copyright 2006, American Chemical Society). 


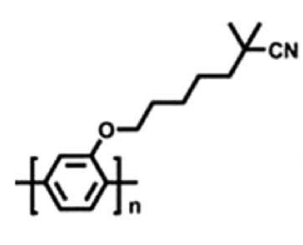

CN-PPP

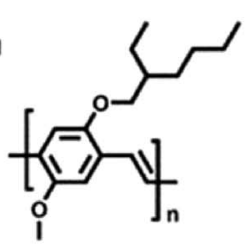

MEH.PPV

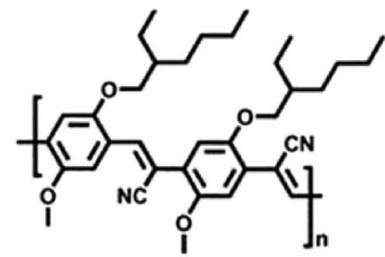

MEH-CN-PPV

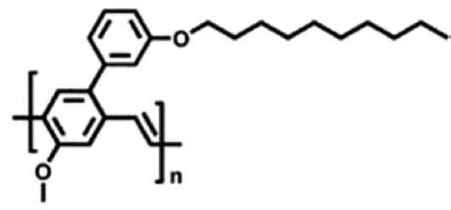

Yellow-PPV

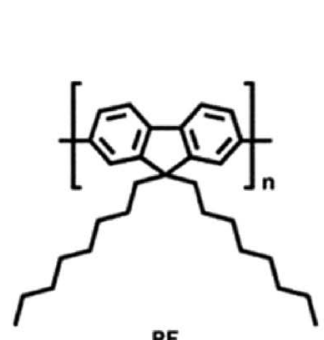

PF

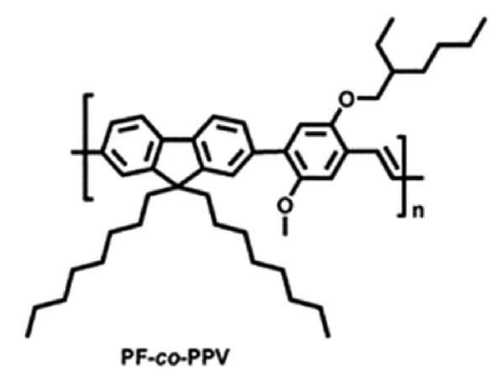

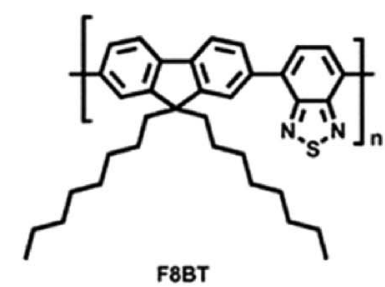

F8BT

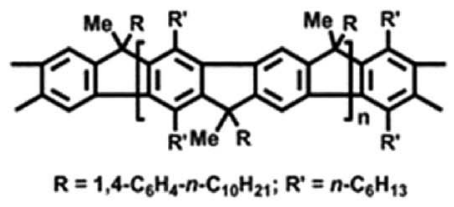

MeLPPP

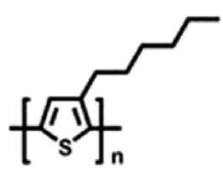

P3HT

Figure 7. Chemical structures of the polymers used in blend systems for hybrid devices. Chemical structures are MEH-PPV, MEH-CN-PPV, P3HT, PF, F8BT, CN-PPP, PF-co-PPV, yellow-PPV and MeLPPP.

high photoluminescence (PL) quantum yields of $>50 \%$ for so-called core-shell NCs like $\mathrm{CdSe} / \mathrm{ZnS}^{125}$ or $\mathrm{CdSe} / \mathrm{CdS},{ }^{126}$ where the large bandgap semiconductors ( $\mathrm{ZnS}$ or $\mathrm{CdS}$ ) epitaxially overgrow the core material $(\mathrm{CdSe})$ and the band edges of the core material lie inside the bandgap of the outer material. Variable surface chemistry of NCs allows for the ease of their processability from different solvents and for their incorporation into different organic matrices. The basic idea behind NC based organic light-emitting diodes (OLEDs) is to achieve full color tuneability in a single host material. Organic semiconductors such as conjugated polymers represent large polymer chains that are soft and flexible. On the other hand, semiconductor NCs as inorganic species are robust. Inorganic semiconductors are well known to change their emission color over a very wide spectral range, while in organic semiconductors this effect is less pronounced and often goes in hand with changed electrical properties. Although organic molecules span the entire visible spectrum in terms of emission wavelength, a change of material required to tune the color of emission can result in a dramatic modification of the charge transport properties and thus of the device characteristics. A key goal of research into hybrid NC-based OLEDs is therefore a separate optimization of charge transport and emission properties, which can be achieved in certain hybrid devices. ${ }^{127}$ Whereas organic semiconductors are typically hole transporting materials, NC solids generally display strongly n-type behavior, ${ }^{128}$ i.e. in most cases preferentially conduct electrons making the two classes of materials a natural choice of partners. Therefore, combination of both components within nanocomposites enhances the range of potential optoelectronic applications.

Since the discovery of electroluminescence from conjugated polymers by Burroughes, Friend, Holmes and coworkers, ${ }^{129}$ there has been considerable industrial and academic interest in semiconducting polymers as the active material for electrolumnicence (EL) applications. There is a passionate pursuit of the design and development of materials that meet application criteria such as desired emission colors with high emission intensity and efficiency, and good environmental stability. In particular, the control of the emission color of chargeaccepting and transporting properties (important for optimizing device efficiency), and of electrical and optical stability (vital factors in determining device lifetimes) must be addressed. In light absorbing applications there is a stronger focus to tune the materials which have broad spectral response to the absorbed light and applying the conductive polymers, which have capacity of charge transport within the phase separated polymer domains on a mesoscopic level (nm-mm). Some of the most common methods to address the above-mentioned issues will be briefly discussed in the following sections.

The charge transport characteristics of only NCs is $\operatorname{low}^{130}$ and it is difficult to obtain an electrical contact to single NCs because of their small size. Taking these aspects together, these particularities of NCs make them attractive materials for fabrication of hybrid semiconductor NC/organic devices as described below. The organic/inorganic compatibility depends on the versatile chemistry of the host polymer. Hence, the polymers are designed to attain both the optoelectronic properties desired for the specific application in mind, and chemical compatibility providing organic/inorganic homogeneous mixtures. In analogy to the already very successful donor/acceptor approach for phosphorescent systems, ${ }^{131}$ wide bandgap semiconducting polymers are used as donor hosts for semiconductor NCs. ${ }^{132}$ In such blend systems, efficient energy transfer from host (polymer) to guest (NCs) takes place when the donor and acceptor moieties are in close spatial proximity and have a sufficient spectral overlap. ${ }^{132-135}$ Energy and charge transfer from the polymer to the NCs requires an energy band offset at the organic/inorganic interface. To date, conjugated polymer hosts used in hybrid device technology include mainly the commercially available p-type wide bandgap polymers. $\mathrm{MEH}$ $\mathrm{PPV}$ is the most common polymer used as host in hybrid lightabsorbing or -emitting devices. ${ }^{136-140}$ Some authors reported yellowPPV, ${ }^{140} \mathrm{CN}-\mathrm{PPV}^{141,142}$ or methylsubstituted ladder-type poly(paraphenylene) (MeLPPP) ${ }^{143}$ as hosts (Fig. 7). Polyfluorene (PF) (n-type polymer), ${ }^{144}$ and several PF copolymers such as PF-co-PPV202 and 

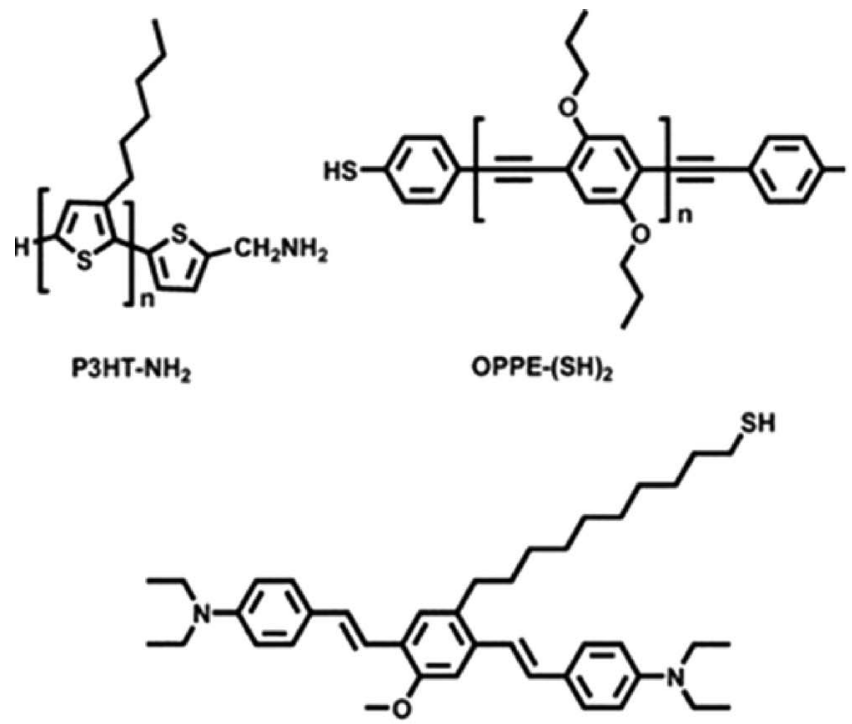

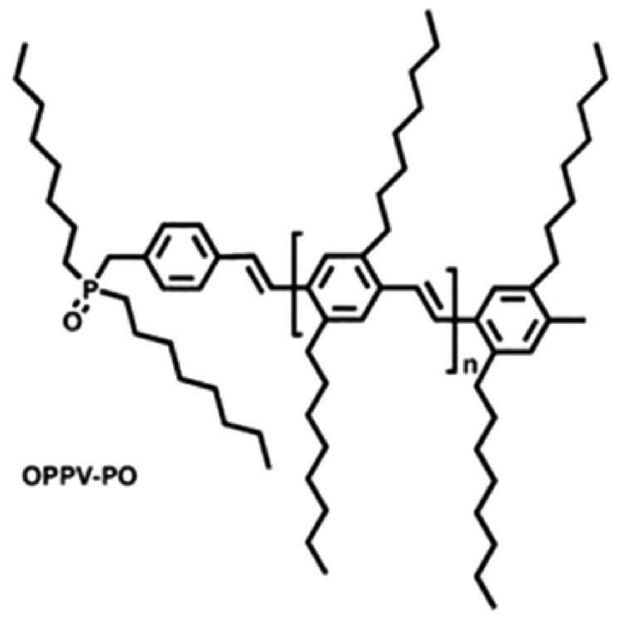

\section{PPV-SH}

Figure 8. Chemical structures of end-group (end groups are connected to NCs) functionalized oligomers: P3HT, ${ }^{157 b} \mathrm{PPV}_{-\mathrm{SH}}{ }^{157 \mathrm{c}}$ and OPPE (SH2) ${ }^{158}$ as well as OPPV-PO. ${ }^{152}$

9,9-dialkylfluorenebenzothiadiazole $\left(\mathrm{F}_{x} \mathrm{BT} ; x=6 \text { or } 8\right)^{144,145}$ were also recently used as polymer matrices in hybrid LEDs (Fig. 6). Hybrid solar cells comprise mainly MEH-PPV ${ }^{137,139,146,147}$ or p-type semiconducting polymers of the polythiophene family such as P3HT ${ }^{146-148}$ or poly(3-octyl-thiophene) (P3OT). ${ }^{149}$ A recent example of a red PF is also available. ${ }^{150}$

Mixing NCs into commercially available cationic PF-based polyelectrolytes (Fig. 8) resulted in improved NC stability, and reduced polymer interchain interactions. ${ }^{145}$ These effects are both desirable in hybrid LEDs as they enhance the device stability and device efficiency by reducing non-radiative losses. A competitive approach to suppress polymer host interchain interaction is the introduction of linear ${ }^{152,153}$ and side-functional, ${ }^{154}$ or dendritic capping ligands. ${ }^{155-157}$ Mixing of NCs with polymers was also shown to result in enhanced energy transfer from the polymer to the NCs. ${ }^{155,158}$

In addition to the polymer blends and surface functional oligomers, functionalized semiconducting polymers have also been designed in order to specifically modify the $\mathrm{NCs}^{85}$ (Fig. 9a). Another approach for polymers uses the side chains, introduced in thienyl monomers, in order to design materials that can be grafted onto the surface of CdTe $\mathrm{NCs}^{156}$ (Fig. 9b). The surface-active side chains of the polymer were utilized in order to trap the NCs via a ligand-exchange reaction ${ }^{158}$ (Fig. 9c).

Plasmonic materials are among the most studied systems in the field of light-matter interactions. ${ }^{160-176}$ Association of plasmonic nanostructure with organic entities, in particular molecules with optical properties, has been intensively investigated for several purposes, such as stabilization of the metal nanostructures or metal-to-dyes interactions. The specific optical response of such metallic nanostructure gives rise to unexpected interactions with optically active molecules.

Surface functionalized metal nanoparticles.-The chemistry and growth mechanisms of metallic nanostructures, especially silver and gold, are nowadays well mastered. This allows a fine control over the size and morphologies (spheres, rods, cubes, stars, bipyramids) and thus a precise tuning of the surface plasmonic resonance (SPR) band from the visible to the near infrared (NIR). ${ }^{163,169,177,178}$ The surface state of the native nanostructures is dependent on the synthesis route, and the particles are usually stabilized through the presence of an organic ligand or surfactants at their surface. The total or par- tial replacement of the stabilizing molecules can be achieved through ligand exchanges reactions with functional systems bearing thiol or thioctic acid pending groups. ${ }^{179}$ These groups possess a strong affinity for the metal surface and ensure efficient binding. The use of electrostatic interactions (i.e., with polyelectrolytes) can also be a way for surface modifi cation. ${ }^{179} \mathrm{~J}$.-Y. Chen et al. used direct interaction between a sulfonated aluminum phtalocyanine and gold nanorods or nanocubes to enhance their fluorescence. ${ }^{180}$ They used it for fluorescence imaging of cancer cells using two-photon excitation in the NIR (Fig. 10).

Since the chromophore to particle distance is a crucial parameter in the control of the charge or energy transfers between the two systems, several spacing strategies were investigated. The synthesis of block copolymers bearing chromophores along the chains showed efficient control over the distance by playing with the polymer structure. ${ }^{181,182}$ The copolymer functionalized with Lucifer Yellow (LY) allowed preparation of luminescent gold hybrid nanostructure (Fig. 11). ${ }^{181}$ The optimized nanostructures were successfully used for cell imaging and photodynamic therapy of cancer cells. ${ }^{181}$

Among the most investigated strategies is the use of core shell nanostructures with metal core and silica based shell, which provides also a good possibility of spacing control between the dyes and the metallic surface. ${ }^{183-192}$ The dye can be either directly incorporated in the silica shell during the synthesis of post-grafted at the surface of the silica. M. A. Noginov used this configuration to generate coreshell structure functionalized at the surface by Oregon green 488 fluorophore encapsulated in the outer silica shell. ${ }^{193}$ This structure, with a spherical gold core of $14 \mathrm{~nm}$ in diameter and a silica shell of $15 \mathrm{~nm}$ thickness, allowed the demonstration of a spaser-based nanolaser in the visible range. ${ }^{193}$ Murphy and co-workers showed that it was possible to have a fine tuning of the distance and easy surface grafting using click-chemistry reactions (Fig. 12a). ${ }^{186}$ They observed enhancement of fluorescence of an IR dye (800CW DBCO) with hotspots (10-fold enhancement) in the range 14-22 nm thicknesses for the silica shell and SPR maxima at $750-800 \mathrm{~nm}$, overlapping the emission spectrum of the dye. The main mechanism was strong coupling between the dye and the metal, and almost no contribution of the scattering effects was detected. Similar strategy but with a different chemical route is to ensure grafting through amide bond by, for example reacting an amine $\mathrm{NH}_{2}$ supported on the silica and a carboxylic acid group (Fig. 12b). ${ }^{184,185}$ 

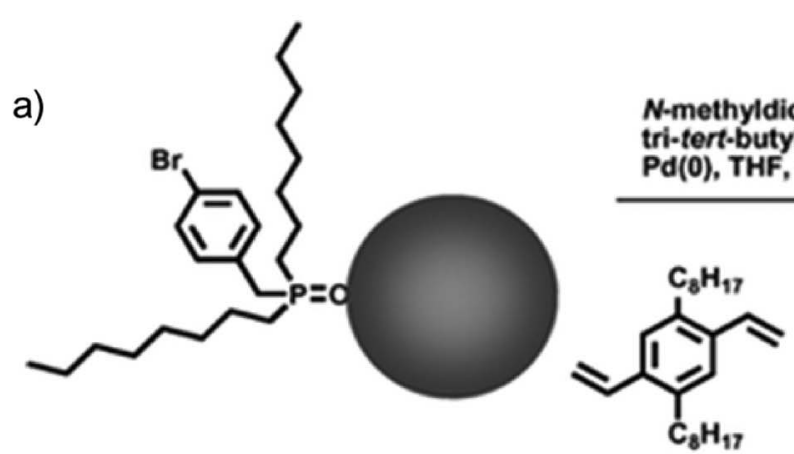

b)

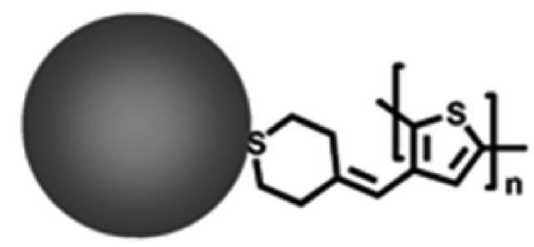

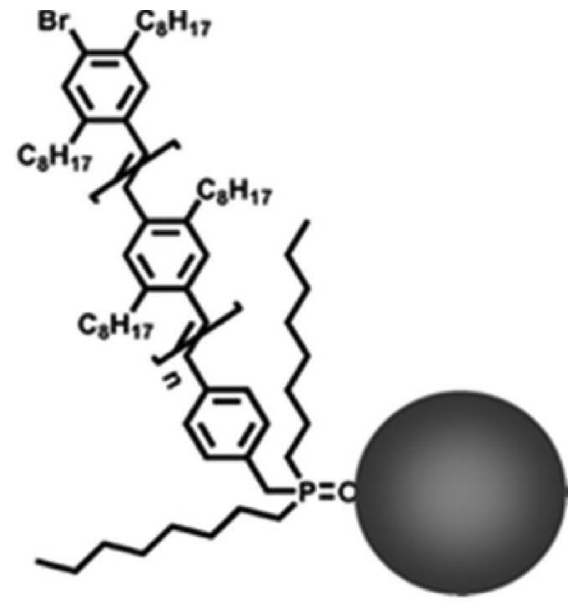

c)

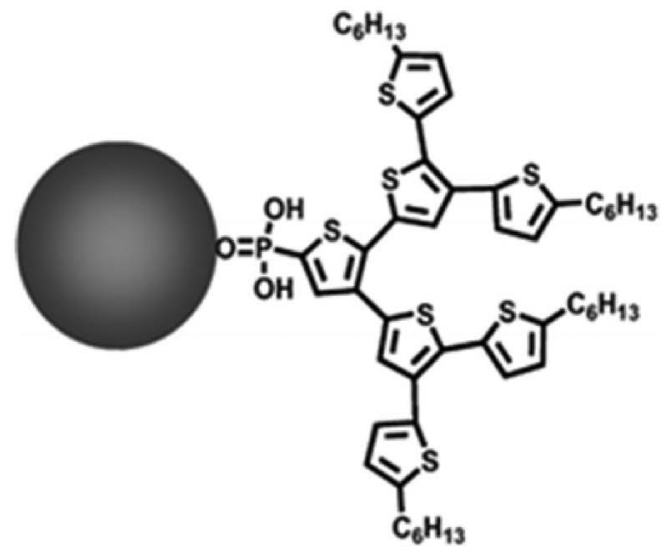

Figure 9. Synthesis of polymer-modified NCs, redrawn according to a), ${ }^{85}$ b) ${ }^{156}$ and c). ${ }^{158}$

Hybrid materials for biomedical applications.-Nanomaterials are novel systems with the potential applications for imaging and therapeutic. ${ }^{193-197}$ Nanoparticulate imaging and therapeutic agents exhibit several advantages, including tunable size, high agent loading, tailorable surface properties, controllable or stimuliresponsive drug release kinetics, improved pharmacokinetics, and biocompatibility. ${ }^{198-200}$ Nanoparticles can be specifically targeted to certain regions of the body (i.e. tumor regions) by conjugation with targeting ligands to enhance their accumulation in the intended parenchymal sites. They can also be engineered to contain multiple agents (i.e. imaging and therapeutic agents) for real-time monitoring of the drug uptake and/or therapeutic responses. Both of these features are difficult

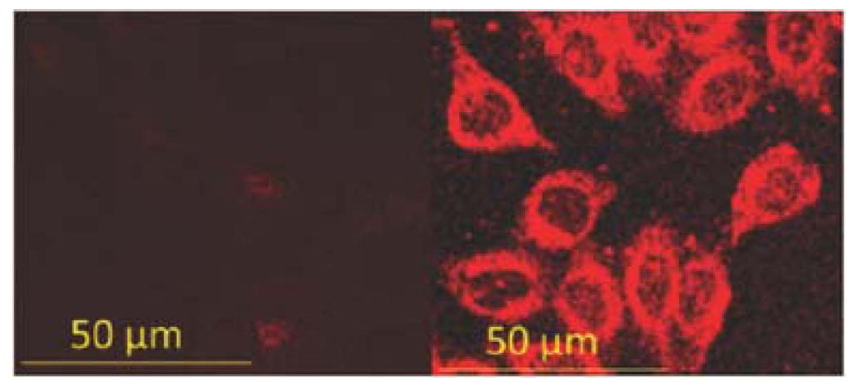

Figure 10. Two-photon fluorescence imaging of cancer cell lines using pure aluminum phtalocyanine (left) and aluminum phtalocyanine combined with gold nanocubes (right) (Reproduced with permission from Ref. 180, copyright 2014, American Chemical Society). to achieve with conventional small molecule drugs. A large number of nanoparticle platforms for biomedical applications have received clinical approval or are in clinical trials. ${ }^{193,196,201}$ The nanoparticle platforms that have been extensively explored for biomedical applications are predominantly either purely inorganic or organic materials. The archetypical inorganic nanoparticles, quantum dots (QDs), are nanomaterials generally composed of elements from either groups II and VI or III and V. ${ }^{202-206}$ They display unique optical properties, including sharp and symmetrical emission spectra, high quantum yields, broad absorption spectra, good chemical and photo-stability, and tunable size-dependent emission wavelengths. ${ }^{204}$ Another class of inorganic nanoparticles that have been evaluated for biomedical imaging applications are metal oxides, such as superparamagnetic iron oxide nanoparticles (SPIO). Iron oxide nanoparticles have been used as contrast agents for magnetic resonance imaging (MRI), and one formulation of SPIO has received FDA approval for clinical use. ${ }^{197}$ Gold nanoparticles with controllable morphologies have been extensively used for biological imaging applications as they can be engineered to exhibit strong absorption in the NIR region. ${ }^{207-210}$ Hybrid nanoparticles are composed of both inorganic and organic components that cannot only retain the beneficial features of both inorganic and organic nanomaterials, but also possess unique advantages over the other two types. For example, the ability to combine a multitude of organic and inorganic components in a modular fashion allows for systematic tuning of the properties of the resultant hybrid nanomaterial.

Silica based hybrid materials for biomedical applications.-The solid silica nanoparticles can be functionalized for biomedical applications using several methods. The simplest method is to entrap hydrophillic functional molecules within the silica matrix via 

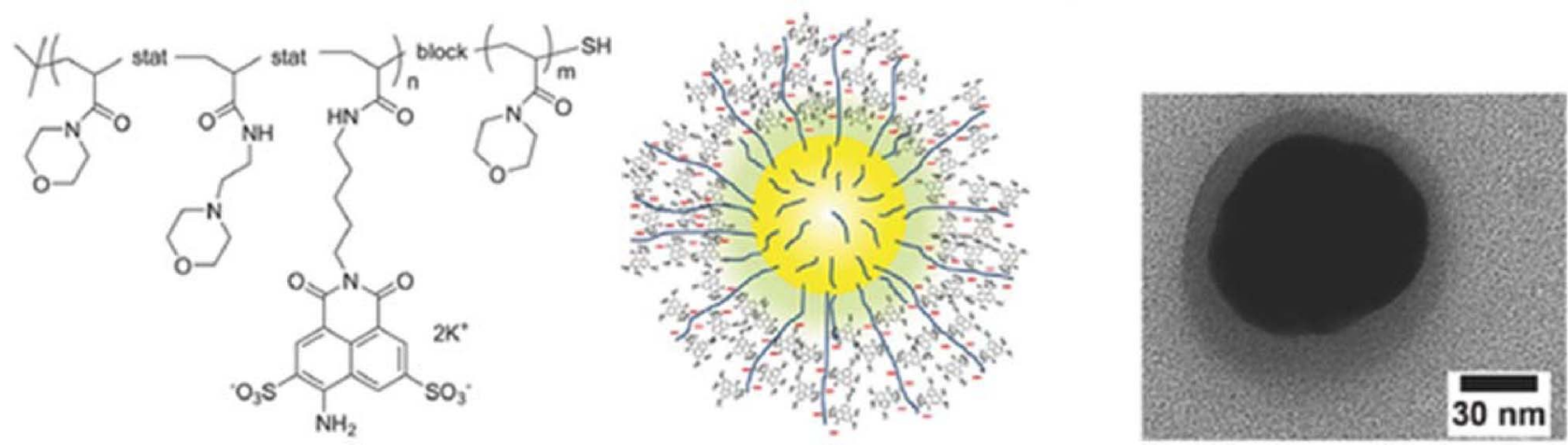

Figure 11. Chemical structure of the diblock copolymer functionalized with LY dyes and AuNPs bearing the luminescent polymers. (Reproduced with permission from Ref. 181, copyright 2013, Elsevier).

noncovalent interactions. This method was widely used to incorporate luminescent dyes (such as the cationic fluorophore $\left.\mathrm{Ru}(\mathrm{bpy})_{3}\right)^{2+}$ within the anionic silica matrix. ${ }^{211}$ However, the entrapped fluorophore can leach out of the nanoparticle under physiological conditions, potentially complicating the data interpretation. Alternatively, imaging or therapeutic agents can be covalently incorporated into silica nanopar- ticles by using trialkoxysilane-derived molecules that contain suitable imaging or therapeutic moieties. These molecules are incorporated within the silica matrix through silanol linkages during particle synthesis, leading to stable hybrid silica nanoparticles with uniform agents throughout the nanoparticle that are protected from the environment. The silica nanoparticles can also be post-synthetically modified by a)
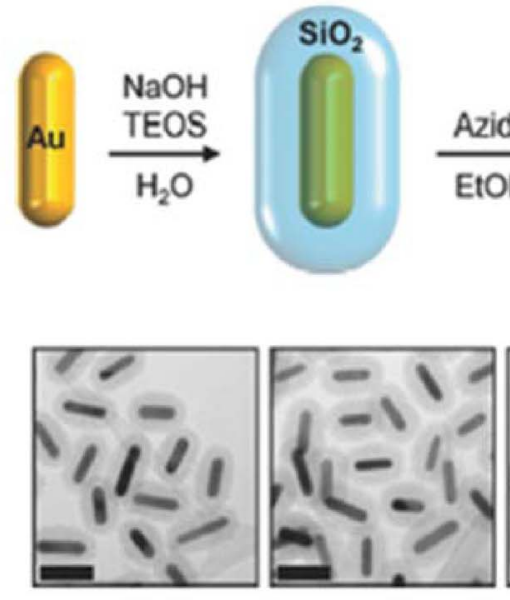

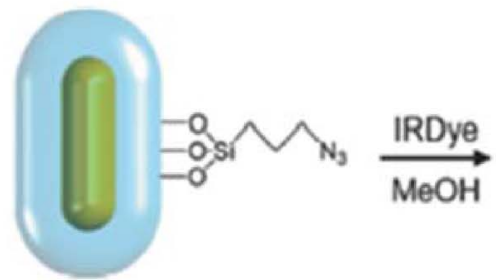

$\underset{\mathrm{MeOH}}{\stackrel{\text { IRDye }}{\longrightarrow}}$
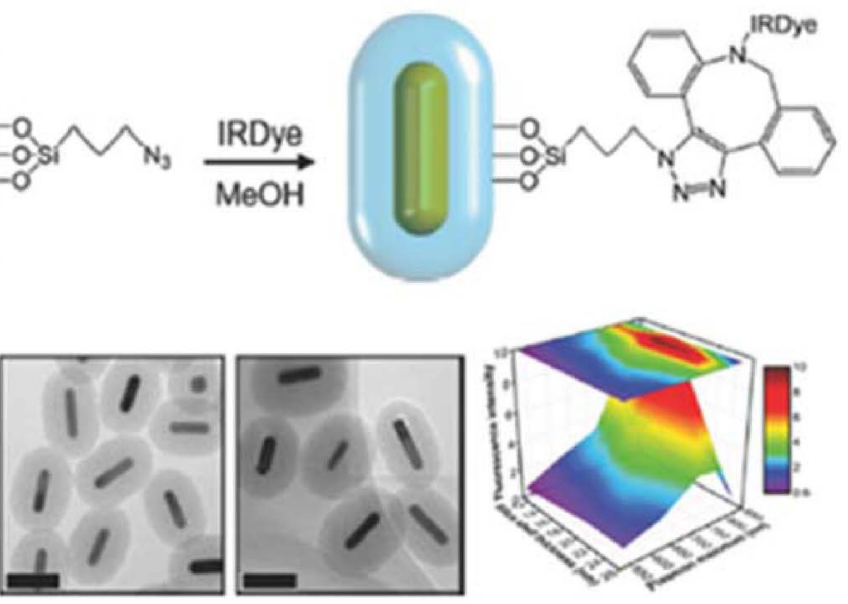

b)
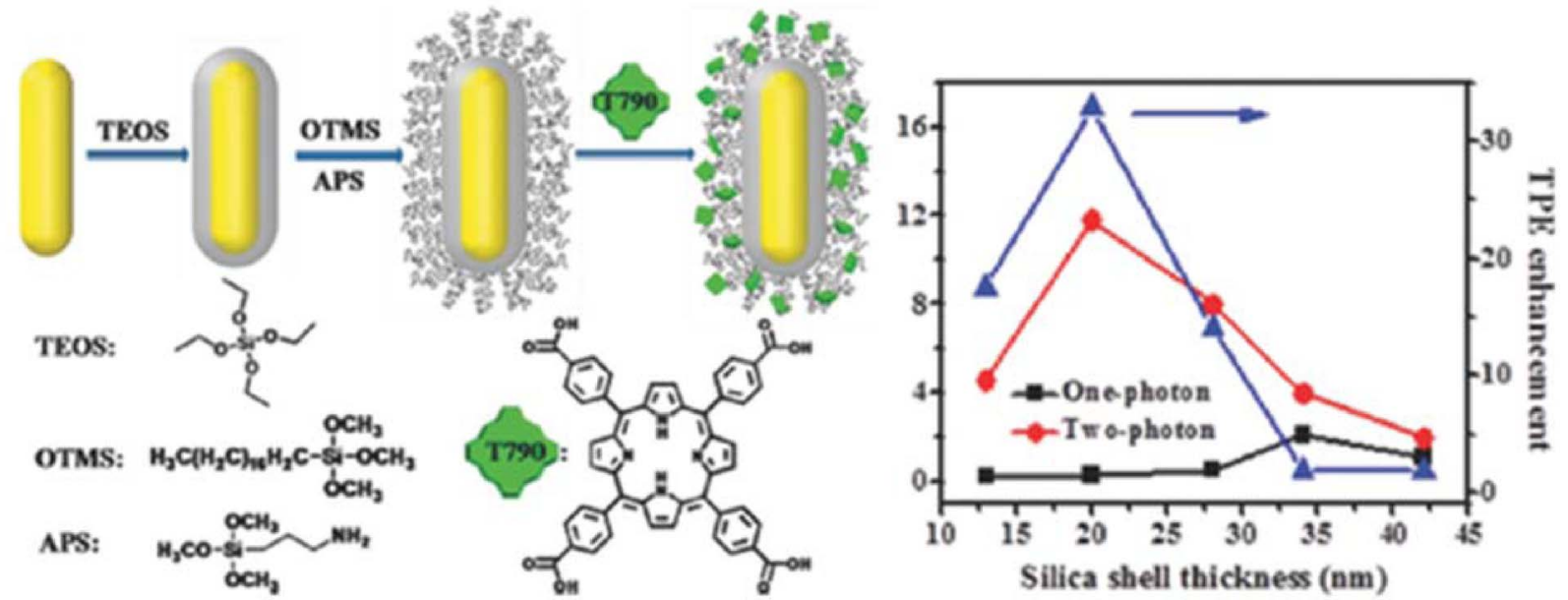

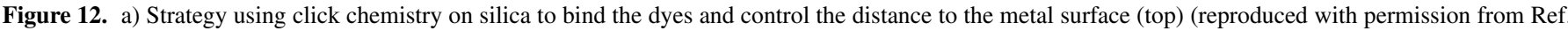

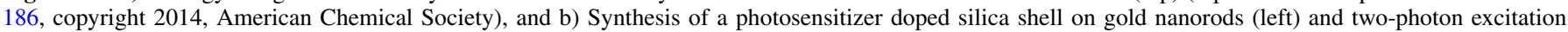

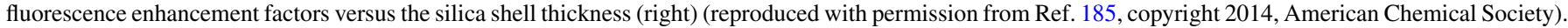



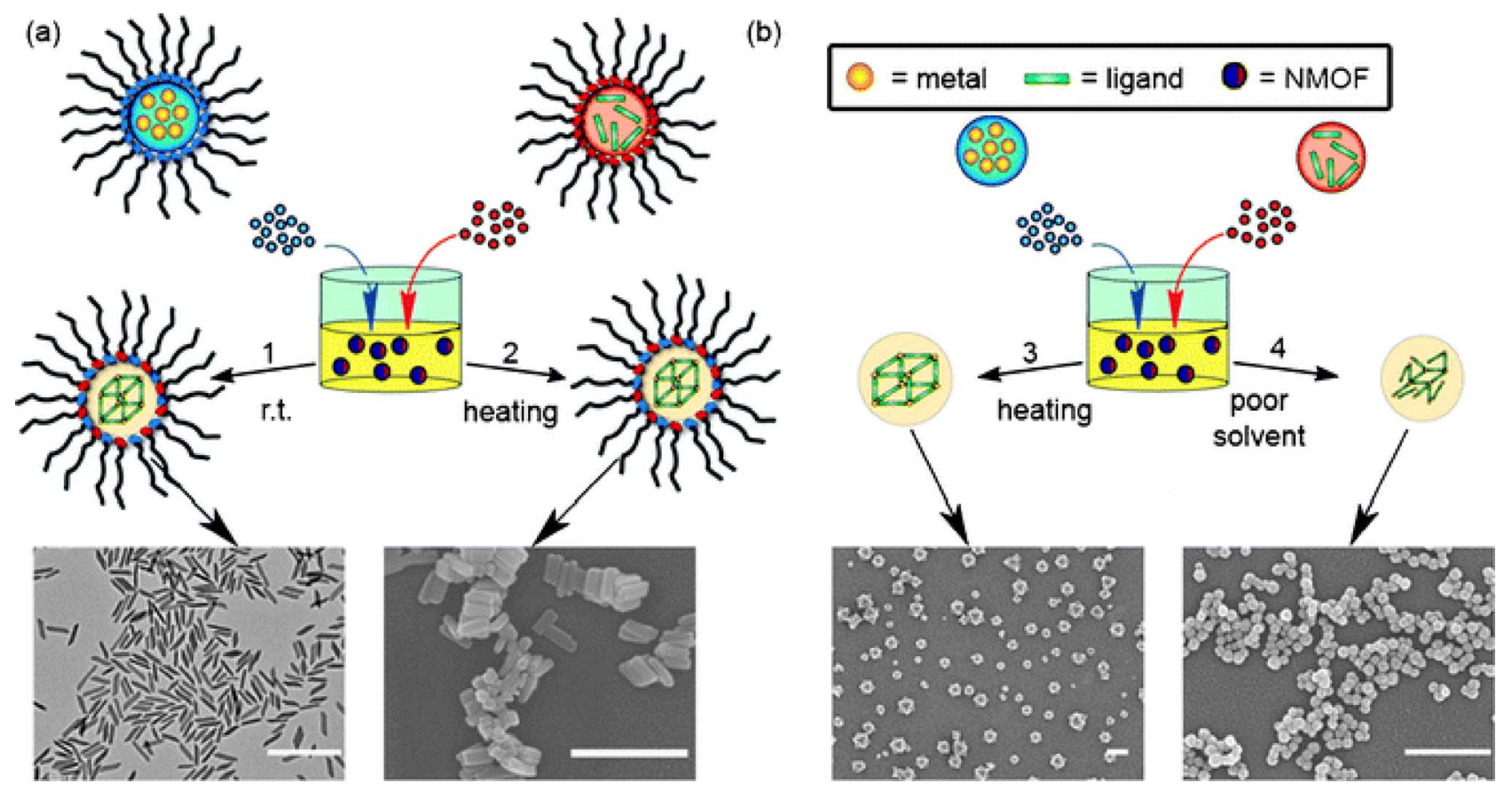

Figure 13. Schematic representation of various methods for making NMOF materials. (a) Water-in-oil, (b) Non-surfactant mediated methods: heating a solution of the metal and the ligand in a coordinating solvent, and EM micrographs show NMOFs of Gd-ligand (reproduced with permission from Ref. 219, copyright 2012, Elsevier).

reacting with trialkoxysilane molecules. Post-synthesis grafting is particularly useful for modifying the particle surface with selected agents that are not stable during the silica particle synthesis. The synthetic versatility also allows the incorporation of imaging and therapeutic cargoes in multi-step sequences. After the desired organic functionality is attached to the silica nanoparticles, the nanoparticles can be further modified through the additional functional group using traditional conjugation chemistry. For example, an amine-modified particle can be reacted with various carboxylate-containing molecules to form a stable amide bond. The cargoes can also be conjugated to the nanoparticle surface by electrostatic interactions. Several types of other inorganic nanoparticles have also been embedded into the silica nanoparticle core to impart imaging functionalities..$^{212,213}$

Hybrid materials for imaging applications.-Nano metal-organic frameworks (MOFs), or coordination polymers are built from transition metal ions and polydentate bridging ligands. Bulk MOFs have shown promise in a number of applications, including nonlinear optics, ${ }^{214}$ selective catalysis, ${ }^{215}$ gas storage, ${ }^{216,217}$ and chemical sensing. ${ }^{218}$ By scaling the materials down to the nano-regime, these materials can be used for biomedical applications. In the silica-based nanomaterials described above, the silica matrix acts as a support for biomedically relevant moieties. In contrast, nano MOF (NMOF) particles can have these moieties incorporated within the framework structure as either the metal connecting points or the bridging ligands. ${ }^{219}$ NMOF nanoparticles are primarily synthesized by four methods reverse microemulsion, surfactant-mediated hydrothermal synthesis, hydrothermal synthesis, and nanoprecipitation (Fig. 13). The first three methods generally lead to crystalline nanomaterials whereas the fourth method tends to afford amorphous nanomaterials. NMOF particles have also been coated with biocompatible polymers via coordination to the surface metal centers. ${ }^{220,221}$ Horcajada and coworkers successfully conjugated several biocompatible polymers (poly(ethylene glycol), dextran, and chitosan) to a variety of iron-carboxylate NMOF particles. Boyes and coworkers have coated Gd-NMOFs previously described by the Lin group ${ }^{222}$ with a copolymer of poly(N-isopropylacrylamide)$c o$-poly(N-acryloxysuccinimide)-co-(fluorescein $O$-methacrylate) by
RAFT polymerization. ${ }^{221}$ Additional imaging contrast agents (substances used to increase the visibility of structures or fluids within the body in medical imaging) or therapeutic moieties could be conjugated to the polymer through the succinimide group.

There have been numerous reports on incorporating organic fluorophores into solid silica nanoparticles (SNPs) for optical imaging. In 2004, Tan and coworkers reported the synthesis of fluorescein isothiocyanate doped SNPs probes in reverse microemulsions. ${ }^{223}$ The resulting $70 \mathrm{~nm}$ NPs were conjugated with the TAT peptide, a cellular penetratingpeptide, and used to label human lung cancer cells in vitro. The in vivo utility of these nanoparticles was demonstrated by selectively labeling rat brain blood vessels via intra-arterial delivery. After the procedure was completed, the brain was imaged using fluorescence microscopy, and nanoparticle fluorescence was observed in brain vessels. These results showed that the TAT-conjugated NPs could selectively cross the blood brain barrier and serve as a potential way to deliver diagnostic or therapeutic agents to the brain. The efficacy of the hybrid SNPs as a dual optical and MR contrast agent was also demonstrated in a collagen-induced arthritis mouse model at $9.4 \mathrm{~T}^{224}$ Mice were injected with saline, $125 \mathrm{mg} / \mathrm{kg}$, or $250 \mathrm{mg} / \mathrm{kg}$ of hybrid SNPs in two doses separated by 6 hours. Luminescence intensity of the paws was measured with a clinical scanner the following day. All control mice displayed minimal luminescence compared to those which received the nanoparticle dose (Fig. 14). The level of luminescence corresponded with the dose received, the clinical disease index, and the level of paw swelling.

Functionalized dye incorporated SNPs with a variety of active groups including hydroxyl, thiol, amine, and carboxyl. ${ }^{225}$ The surface characteristics of NPs play an important role in the uptake of particles by certain types of cells. For example, amino-terminated particles were taken up more efficiently by pancreatic cancer cells than carboxyl-terminated particles. The carboxyl groups present on the carboxyl-terminated particles were used to conjugate various bioactive molecules, such as transferrin and the monoclonal antibodies anti-claudin 4 and anti-mesothelin, allowing for targeted delivery to pancreatic cancer cells. The increased uptake of these targeted particles was demonstrated in vitro. A similar experiment was demonstrated by He and coworkers ${ }^{226}$ who successfully functionalized the 


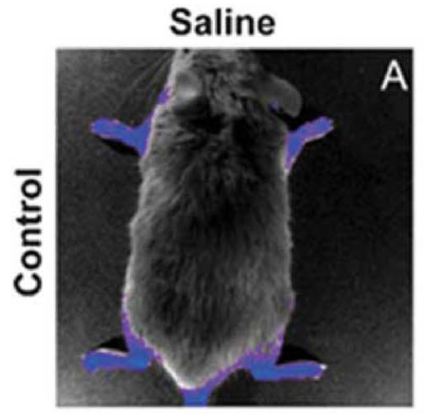

MNP: $125 \mathrm{mg} / \mathrm{kg}$
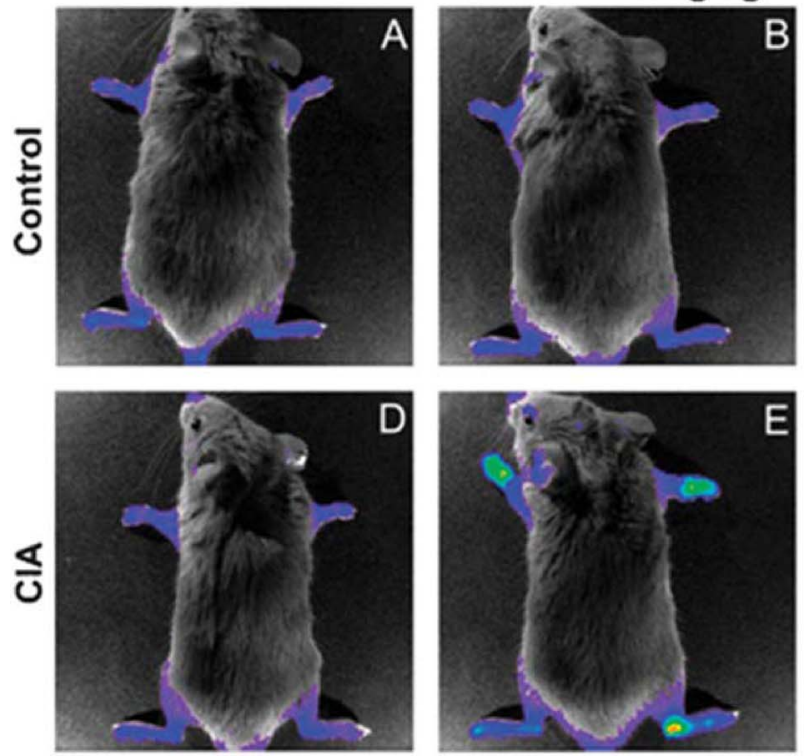

MNP: $250 \mathrm{mg} / \mathrm{kg}$
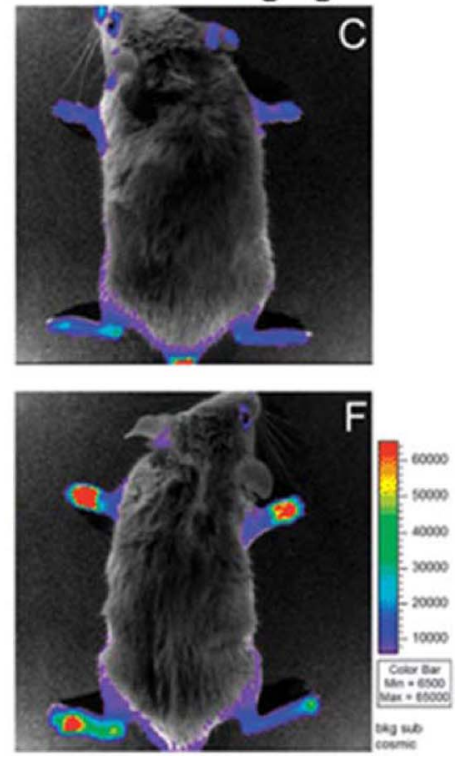

Figure 14. Upper Control animals that did not have arthritis intravenously injected with two separate doses of (A) saline, (B) $125 \mathrm{mgMNP} / \mathrm{kg}$, or (C) $250 \mathrm{mg}$ MNP/kg 12 hours before optical imaging. (lower) CIA animals with arthritis intravenously injected with (D) saline, (E) $125 \mathrm{mg} \mathrm{MNP} / \mathrm{kg}$, or (F) $250 \mathrm{mg} / \mathrm{kg}$, (reproduced with permission from Ref. 223, copyright 2004, Royal Chemical Society).

surface of SNPs containing Nile Red with amine groups and conjugated the targeting moieties apo-transferrin and folic acid. Both of these targeting moieties resulted in increased uptake of the particles by HeLa cells in vitro.

Hybrid SNPs have been used in drug delivery and therapy applications. Prasad and coworkers described the use of an organically modified silica nanoparticle for photodynamic therapy (PDT). ${ }^{227}$ PDT is a light-activated treatment for cancer and other diseases, and works by utilizing light sensitive drugs (i.e. photosensitizers) that can be preferentially localized in malignant tissues. Its therapeutic effect is initiated by photoexcitation of the localized photosensitizer to generate cytotoxic species such as singlet oxygen $\left({ }^{1} \mathrm{O}_{2}\right)$. This leads to selective and irreversible destruction of diseased tissues, without damaging adjacent healthy ones. The main drawback to this therapy is that currently approved PDT photosensitizers absorb in the visible spectral region below $700 \mathrm{~nm}$, where light penetration into the skin is only a few millimeters. This problem can be overcome by combining a two-photon absorbing (TPA) dye with the photosensitizer. Here, the photosensitizer is indirectly excited through fluorescence resonance energy transfer (FRET). In this work, a known photosensitizer and a two-photon energy donor were co-encapsulated in $30 \mathrm{~nm}$ silica NPs (Fig. 15). Upon two-photon irradiation, the photosensitizer is excited

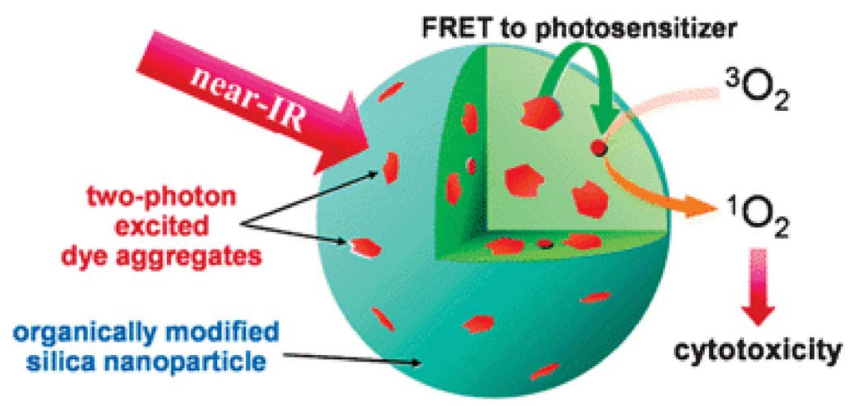

Figure 15. Representation of an organically modified SNP co-encapsulating a photosensitizing drug and photon absorbing fluorescent dye aggregates for two-photon photodynamic therapy, (reproduced with permsssion from Ref. 227, copyright 2007, American Chemical Society). as a result of intraparticle FRET from the two-photon absorbing dye, resulting in the generation of singlet oxygen. The uptake of these particles was demonstrated through fluorescence imaging of HeLa cells. Upon two-photon irradiation, HeLa cells that had been incubated with the nanoparticles exhibited drastic morphology changes associated with cell necrosis, apparently induced by the reactive oxygen species generated by the photosensitizer.

Mesoporous SNPs (MSNPs) have been extensively evaluated as delivery vehicles for a variety of cargoes. Victor Lin and coworkers have also developed several MSNP-based delivery systems containing stimuli-responsive pore caps (such as $\mathrm{CdS}$, $\mathrm{Au}$, and superparamagnetic $\mathrm{Fe}_{3} \mathrm{O}_{4} \mathrm{NPs}$ ) to allow for the controlled release of entrapped molecules. ${ }^{228,229}$ As an example shown in Fig. 16, the gold nanoparticles were conjugated to the MSNP materials with a photolabile linker. ${ }^{230}$ The hybrid system releases the Au nanoparticle pore caps when exposed to UV. This system was used to deliver paclitaxel to human liver and fibroblast cells. Other drug molecules and neurotransmitters, such as vancomycin and adenosine triphosphate (ATP), have also been delivered using this strategy. ${ }^{228,229}$

A double drug delivery system was also developed based on capped MSNPs. ${ }^{231}$ Boronic acid functionalized MSNPs were loaded with cyclic adenosine monophosphate (cAMP), an important cellular signaling molecule. The pores of the material were then capped with fluorescein-labeled insulin. Release from the material was shown to be triggered by saccharides, as they form more stable conjugates with the boronic acids on the nanoparticles. Feng and coworkers demonstrated the use of a cross-linked polymer network as a "gatekeeper" for MSNPs (Fig. 17). ${ }^{232}$ 2-nm thick poly( $N$-acryloxysuccinimide) was anchored to the MSNPs surface through reversible additionfragmentation chain transfer (RAFT) polymerization and then crosslinked by adding cystamine. The ability to control the release of cargos was demonstrated by entrapping rhodamine B inside the MSN before cross-linking of the polymer. A light-activated nanoimpellercontrolled drug carrier based on MSNs was recently designed by taking advantage of the well-known cis-trans isomerizationin the azobenzene derivative (4-phenylazoaniline). ${ }^{233}$ The anti-cancer drug camptothecin loaded into this system could be trigger released by irradiation at $413 \mathrm{~nm}$. After incubating the cells with the drug-loaded MSN, cell death was only observed after irradiation. A related trigger release system based on MSN supported polyelectrolyte multilayers 


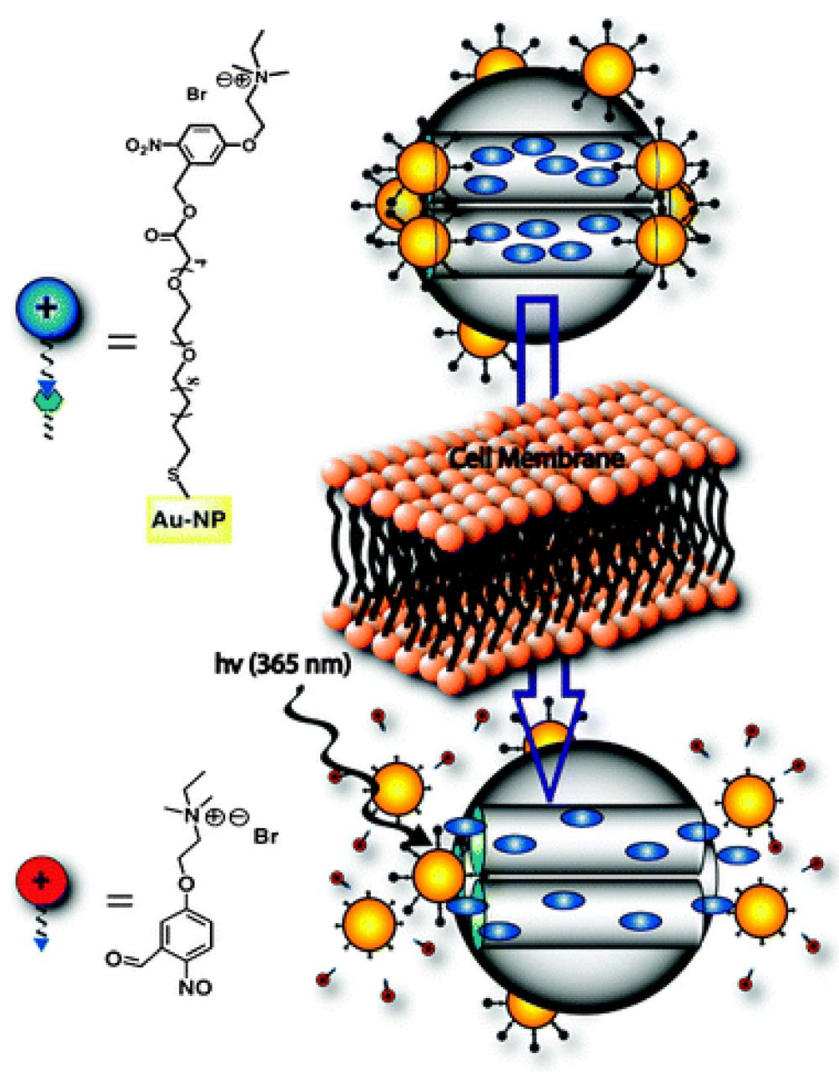

Figure 16. Graphical sketch of the AuNP -capped MSNP-based drug delivery system, (reproduced with persmission from Ref. 230, copyright 2009, American Chemical Society).

was developed by Wang and coworkers for controlled delivery of doxorubicin in vitro. ${ }^{234}$

Hybrid materials for electronics.-Future ubiquitous electronic devices require versatile features, such as being lightweight and exhibiting portability, wearability and flexibility with a superior mechanical stability. Organic materials offer structural flexibility, convenient processing, tunable electronic properties, photoconductivity, efficient luminescence, and the potential for semiconducting and even metallic behavior. Inorganic compounds provide the potential for high carrier mobilities, bandgap tunability, a range of magnetic and dielectric properties, and thermal and mechanical stability. In addition to combining distinct characteristics, new or enhanced phenomena can also arise as a result of the interface between the organic and inorganic components. Electron-transfer processes at organic-inorganic interfaces have, for example, been examined. ${ }^{235-237}$ Dielectric modulation in organic-inorganic systems has also led to enhanced binding energies for excitons in the inorganic framework of the structure, as a result of the smaller dielectric constant and reduced screening in the organic component of the hybrid. ${ }^{238}$

In electronic materials polymer solar cells have attracted enough attention over the past several decades due to their advantageous properties, including lightweight, flexibility, and solution processability. ${ }^{239}$ However, the electron mobility of most of conjugated polymers (CPs) is a few orders of magnitude lower than their hole mobility, thereby resulting in the charge carrier recombination in photoactive layer. In this regard, incorporating electron acceptors such as fullerene derivatives or semiconductor inorganic nanocrystals (NCs) is of key importance. ${ }^{240}$ The bulk-heterojunction structure has been recognized as the most successful architecture for polymer solar cells. ${ }^{241-244} \mathrm{Re}-$ cently, BHJ solar cells composed of CPs and fullerene have achieved energy conversion efficiency up to $6 \sim 8 \%{ }^{244}$ Inorganic nanocrystals (NCs) possess size-dependent optical and electronic properties that open up opportunities for use in solar cells, ${ }^{245}$ LEDs, ${ }^{246}$ tunable lasers, ${ }^{247}$ bio-sensors,${ }^{248}$ and bio-imaging applications. ${ }^{249}$ In particular, incorporating NCs (e.g., CdS, CdSe, CdTe, PbS, ZnO, etc.) in polymer solar cells would facilitate the charge dissociation and transport owing to the large surface area, high electron affinity, and excellent intrinsic carrier mobility of NCs. ${ }^{250}$ In this context, semiconductor NCs have been introduced as electron acceptors into hybrid solar cells (e.g., poly(3-hexylthiophene)/CdSe NCs; $\mathrm{P} 3 \mathrm{HT} / \mathrm{CdSe}){ }^{251,252}$ However, simply physically mixing CP and NC often results in micro-scale phase segregation, thus limiting the resulting device performance. ${ }^{253-254}$ In addition, the insulating organic ligands capped on the $\mathrm{NC}$ surface hinder the electronic interaction with CPs. As a result, the ability to directly tether CPs on the NC surface would be an elegant means of achieving the intimate contact between CPs and NCs to prevent such microscopic aggregation. To this end, direct grafting and in-situ growth methods have been explored to create $\mathrm{CP}$-grafted NCs and naked NCs in the CP matrix, respectively, for hybrid solar cells. ${ }^{255}$ However, polymer based solar cells often suffer from insufficient light absorption despite the strong absorption coefficient of most CPs. This is because the thickness of photoactive layer is restricted due to the short charge carrier diffusion length as well as the use of large bandgap of CPs which fails to absorb solar photons in NIR region. In this regard, plasmonic metallic NCs (e.g., Au and Ag) and NIR-absorbing NCs (e.g., PbS and PbSe) have been utilized to further harvest solar energy. ${ }^{256}$ Moreover, despite the
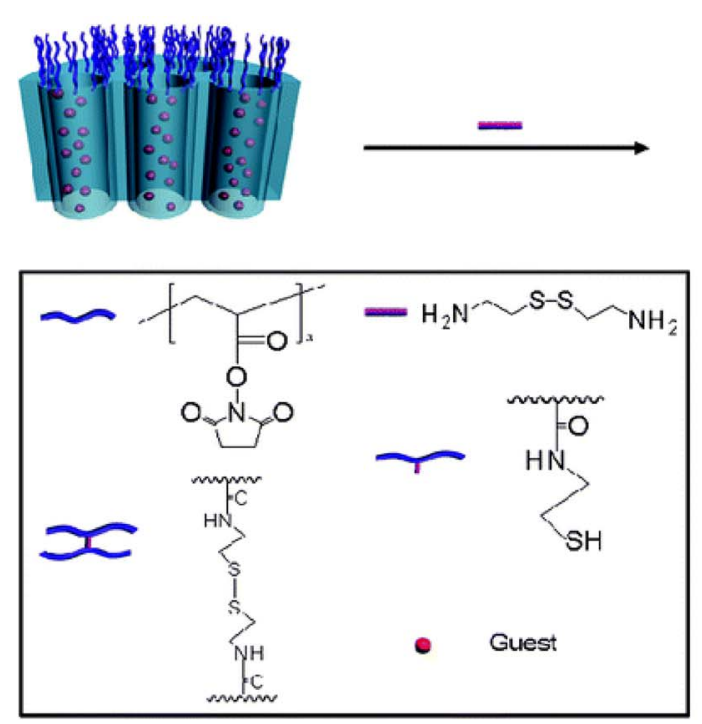
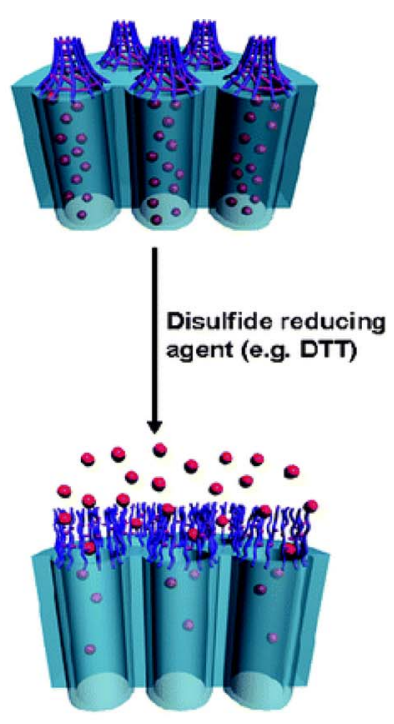

Figure 17. Representation of redox responsive nano-gated ensemble based on polymeric network-capped mesoporous silica, (reproduced with permission from Ref. 232, copyright 2008, American Chemical society). 


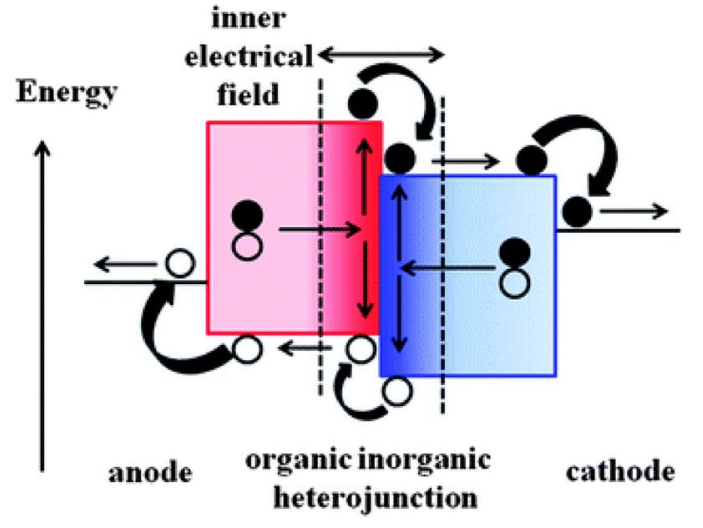

Figure 18. Graphic representation of operating principles of an organicinorganic solar cell. The electron (O) and hole (o) transfer are shown with arrows, (reproduced with permission from Ref. 257, copyright 2013, Royal Society of Chemistry).

significant developments in interfacial treatment for efficient charge separation, control over the architecture of photoactive layer comprising $\mathrm{CP} / \mathrm{NC}$ nanocomposites has not yet been exploited to its full potential for charge transport due largely to the difficulty in controlling the film morphology during the spin-casting process. Ideal device geometry should consist of bicontinuous pathway for both holes and electrons, and thus enhance charge transport as well as reduce the charge recombination.

So called 1st generation solar cells based on crystalline and polycrystalline silicon $(\mathrm{Si})$ with power conversion efficiencies (PCE) in the range $18-25 \%$ are still dominating the photovoltaics (PV) market. 2nd generation thin film solar cells based on II-VI semiconductors, copper indium gallium selenide, and amorphous $\mathrm{Si}$ possessed the best PCE of close to $20 \% .^{257}$ The 3rd generation solar cells were developed to pursue high PCE and low costs for special applications, such as tandem cells, light-condensed cells, organic photovoltaics, dyesensitized solar cells, organic-inorganic hybrid solar cells and so on. Generally, the PCEs and lifetimes of solar cells containing organic components were less efficient than those of traditional 1st and 2nd generation solar cells. However, the low fabrication cost, flexibility and light weight have made them suitable for several special applications. Organic-inorganic hybrid solar cells could adopt the merits of inorganic materials, such as stability, high carrier mobility and compatible fabricating process, and utilize the advantages of organics, such as enhanced light absorption at a wide range of wavelengths, adjustable molecular structures for energy band alignment, facile solution processability, and so on. Similar to the Si p-n junction solar cells, the general operating principle of organic-inorganic hybrid solar cells also involves the following steps: light absorption, exciton generation and diffusion, exciton dissociation to carriers at the junction interface and carrier transportation and collection, which is schematically shown in Fig. 18.

Lot of effort has been made to improve the performance of hybrid solar cells. Based on the interface configuration of $p-n$ junctions, hybrid solar cells have been developed by three methods, which are schematically shown in Fig. 19.257 The deposition of an organic film on an inorganic film can instantly form an hybrid solar cell, as depicted in Fig. 19a. Sandwiched blend of inorganic QDs, NPs and nanowires (NWs) with organic semiconductors shown in Fig. 19b. The main advantage of this configuration is the cost-effectiveness and flexibility of the fabrication process. However, dead-ends (domains which does not produce photocurrent) and short circuiting of charges could not be avoided in this type of solar cell. In order to further enlarge the interface area and benefit carrier transportation, ordered nanostructures were adopted for use in hybrid solar cells, as in Fig. 19c.

Many reviews have highlighted the development and prospects of hybrid solar cells. Due to their facile and cost-effective fabrication, (a)

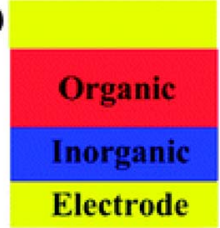

(b)

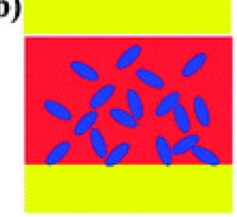

(c)

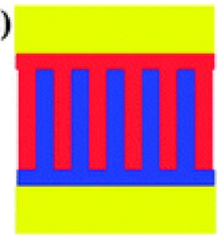

Figure 19. Configuration of interface between organic-inorganic solar cells: (a) planar films, (b) blending with an active layer and (c) use of ordered nanostructures, (reproduced with permission from Ref. 257, copyright 2013, Royal Society of Chemistry).

the most popular topic was polymer-QDs/NP mixed solar cells, as shown in Fig. 17b..$^{258-260}$ The maximum PCE achieved was about $5 \%$ and a theoretical prediction of $10 \%$ has been reported. ${ }^{261,262}$ Their performance was dominated by the absorption spectra of the active components, the interface morphology of the junction, and the blending composition. ${ }^{263-266}$ The synthesis route, dispersed solvents and surface termination of inorganic QDs/NPs also affected the properties of the Hybrid solar cells. ${ }^{267}$ Polystyrene sphere template-assisted synthesis can generate several kinds of one-dimensional nanostructured arrays, such as nanopillars, nanorods, and NWs. ${ }^{268}$ The state-of-the-art research on hybrid organic-inorganic solar cells based on nanostructured arrays have been explored. ${ }^{269-270}$ The most popular organics for hybrid solar cells are summarized in Fig. 20. The balance between performance in practical applications and cost may be one of the important considerations for developments in the near future.

Hybrid materials for electrical memory devices.-Functional hybrid inorganic/organic nanocomposites provide a frontier for unique functions with promising applications in nonvolatile memory devices. Organic bistable devices fabricated utilizing nanocomposites have emerged as excellent candidates for potential applications in the next-generation nonvolatile memory devices. A typical structure for a hybrid organic/inorganic nonvolatile memory device consists of composite organic molecules: metal/semiconductor nanoparticles layer sandwiched between two metal electrodes. The device area is defined by the overlap between the top and the bottom electrodes; therefore, a very high memory density can be easily achieved by using cross-bar arrays. ${ }^{271-275}$ The organic material used can consist of small organic molecules or polymers. Small organic molecules have low molecular weight and can be deposited under high vacuum without decomposition by using thermal evaporation. Polymer molecules, on the other hand, consist of much larger molecules with long chains of repeating monomer units and will decompose before evaporation begins. One of the main advantages provided by organic materials and devices is low fabrication cost and simplicity. The fabrication of these devices through thermal evaporation requires high vacuum and stringent conditions to control the morphology of the organic active layer. ${ }^{276}$ As alternatives to the more elaborate processes of vacuum evaporation and deposition of organic and inorganic molecular materials, solution processes, including spin-coating, spray-coating, dip-coating, roller-coating and ink-jet printing, are well known and can be used to deposit polymer materials on a variety of substrates, such as glasses, plastics, metal foils and wafers. ${ }^{277-280}$ The simplest structure for a hybrid memory device fabricated utilizing the solution method is a single-polymer layer embedded with inorganic nanomaterials and sandwiched between two metal electrodes, as shown in Fig. 21. ${ }^{277}$ Fabrications of single-layer-structured nonvolatile memories based on various organic/inorganic hybrid nanocomposites have been reported. Inorganic species used in these memories include semiconductor nanoparticles ( $\mathrm{ZnO}, \mathrm{CdSe}, \mathrm{Si}, \mathrm{CuO}$ and so on) and metal nanoparticles ( $\mathrm{Au}, \mathrm{Ag}, \mathrm{FeNi}$ and so on). ${ }^{277-287}$

One of the problems that single-layer memories face is the cross talk of neighboring memory cells due to the presence of parasitic conduction paths, which causes misreading during the operating process. A possible solution to this problem is to use one diode and one 


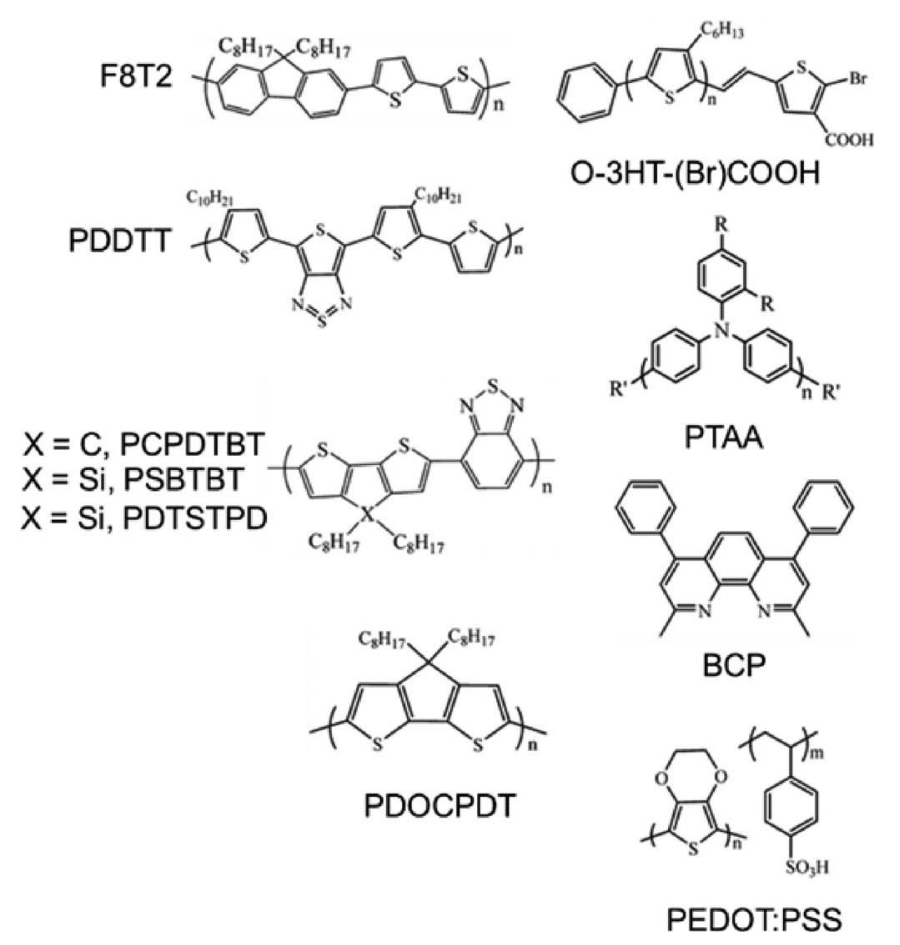

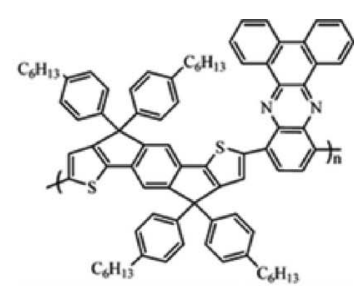

PIDT-PhanQ

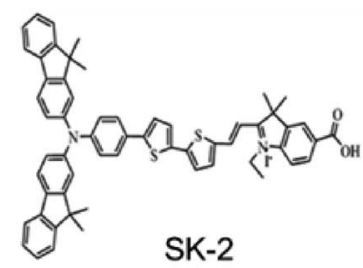

PECz-DTQx

Figure 20. Chemical structure and abbreviations of the organic semiconductor components in hybrid solar cells.

resistor or one transistor and one resistor structures to construct an individual memory cell with high reading accessibility. ${ }^{278,279}$ Therefore, multilayer structures might be required to realize one diode/one resistor or one transistor/one resistor cells. Some works concerning the formation of multilayer-structured nonvolatile memory devices by using PI materials have been reported, and their memory effects have been demonstrated as well. ${ }^{280-282}$ Depending on the $I-V$ characteristics, three types of nonvolatile memory effects, write-once-read-manytimes and unipolar and bipolar electrical switching, can be observed for hybrid devices. In the case of a nonvolatile memory based on hybrid nanocomposites, the memory effect is strongly correlated with the presence of inorganic nanomaterials, for example, $\mathrm{ZnO}$ QDs, $\mathrm{Au}$ nanoparticles, CdSe nanoparticles and carbon nanotubes, embedded in a polymer matrix because the current difference between the $\mathrm{ON}$ and the OFF states for the polymer-only device is negligible. ${ }^{283}$ Recently, for a hybrid device containing Au QDs embedded in a PI layer, Wu et al. ${ }^{284}$ reported an electrical bistability with an ON/OFF ratio of $\sim 10^{8}$, which is one of the largest values for a stable hybrid memory device. In the case of a unipolar nonvolatile memory, due to the presence of a negative differential resistance in the $I-V$ characteristics, the OFF state can be regained when a forward bias is given

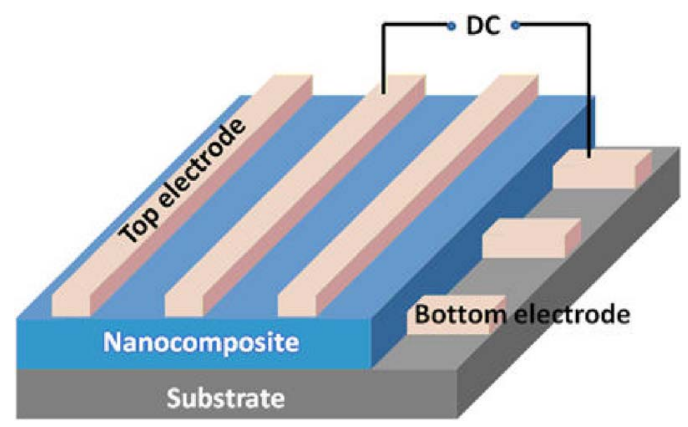

Figure 21. Schematic representation of the hybrid memory device, (reproduced with permission from Ref. 277a, copyright 2012, Nature Publishing Group). to the memory device. ${ }^{285,286}$ For bipolar memories, the OFF state of the hybrid device can be recovered by applying a reverse bias voltage, which is equivalent to the 'erasing' process in a digital memory cell. One of the main advantages of a nonvolatile memory device based on hybrid nanocomposites is the possibility of realizing flexible memories at extremely low fabrication cost. These hybrid devices can be processed at low temperatures and, therefore, are regarded as one of the most important types of information-storage components for future stretchable/portable electronic device applications. ${ }^{287-291}$ For example, Kim and Lee ${ }^{287}$ developed nonvolatile memory devices on plastic substrates (PES) based on a pentacene layer embedded with self-assembled gold nanoparticles, as shown in Fig. 22. The nano floating gate memory exhibited a large memory window that could be maintained for $>1$ year. Nonvolatile electrical bistability of a hybrid device fabricated utilizing $\mathrm{CdSe} / \mathrm{ZnS}$ nanoparticles embedded in a conducting poly $(N$-vinylcarbazole $)$ polymer layer on flexible polyvinylidene difluoride and polyethylene terephthlate substrates has also been reported. ${ }^{291}$ The results indicate that the hybrid bistable memory devices are prospects for potential applications in flexible nonvolatile flash memory devices. ${ }^{291}$

Also, the area of functional organic thin film transistors (OTFTs) have attracted extensive research efforts in recent years because of their tremendous emerging impact on applications for flexible electronics. ${ }^{292-296}$ Especially, OTFTs can serve as the basic and reliable media for electrical memories and switching devices in the increasingly important information technology. OTFTs with nonvolatile memory effects are one potential option based on their nondestructive readout and single transistor architectural compatibility for easily integrated devices. ${ }^{297-301}$ Organic thin film transistor (OTFT)-based nonvolatile memory devices using the hybrid nanocomposites of semiconducting poly(9,9-dioctylfluorenealt-bithiophene) (F8T2) and ligand-capped Au nanoparticles (NPs), thereby serving as a charge storage medium have been fabricated (Fig. 23). ${ }^{302}$

Hybrid materials for flexible electronics.-Aligned with the fast expansion of the personal information platform and Internet of Things (IoT), flexible and stretchable electronic devices are being seamlessly 


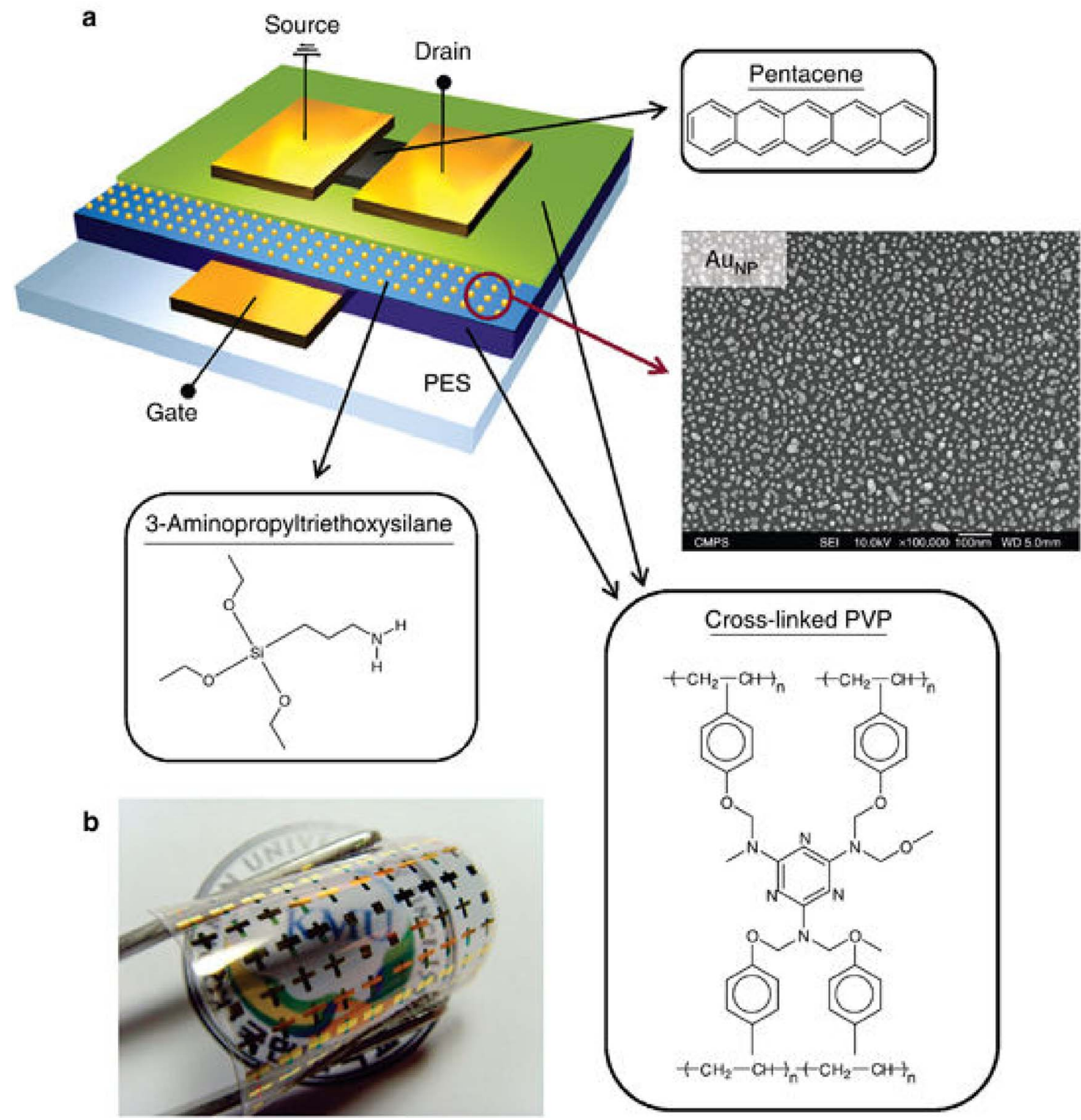

Figure 22. a) 3D representation diagram of the flexible hybrid memory device architecture. Patterned Ti/Au on a PES plastic substrate was used as the gate electrode, and a pentacene active layer and gold source/drain contacts were formed to make the organic transistor-based memory devices, $b$ ) Photograph of a fabricated flexible organic memory device, (reproduced with permission from Ref. 287, copyright 2010, American Chemical Society).
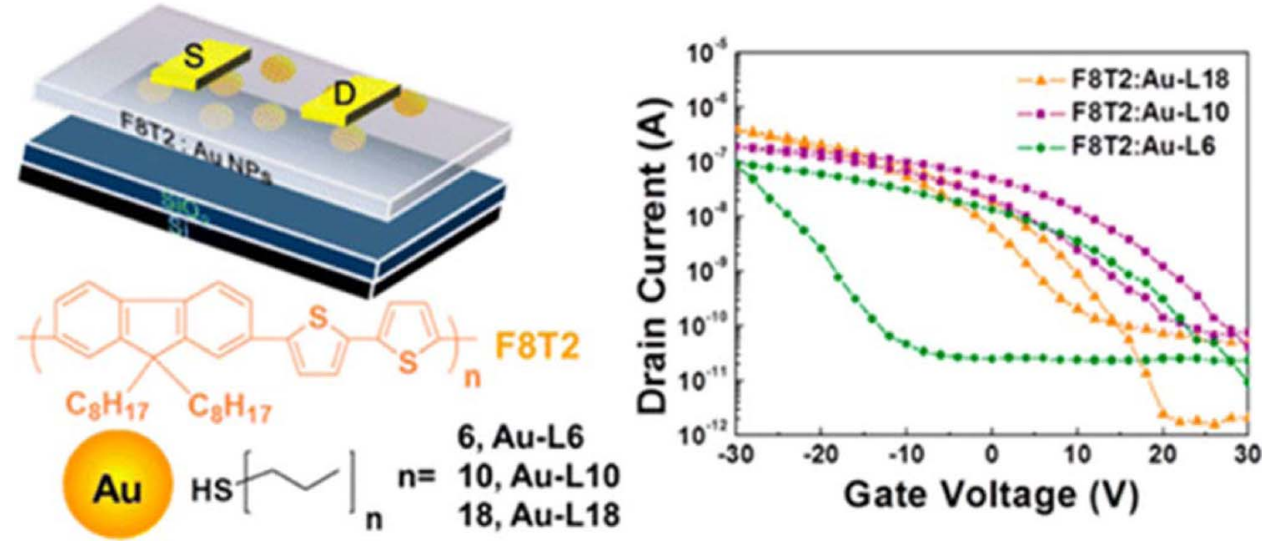

Figure 23. Schematic representation of hybrid nonvolatile organic thin film transistor memory device based on semiconducting polymers and AuNPs, (reproduced with permission from Ref. 302, copyright 2013, American Chemical Society). 

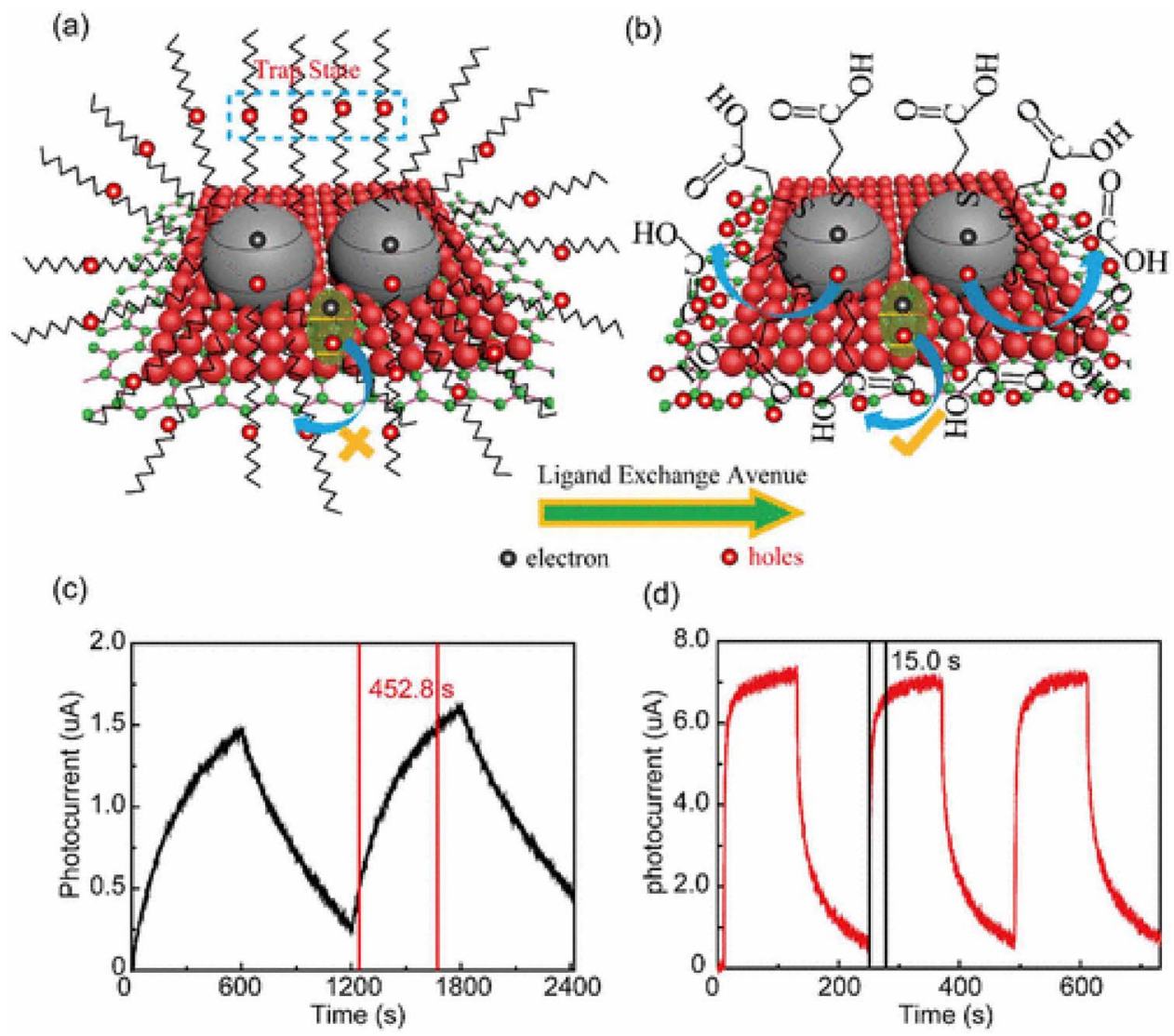

(d)

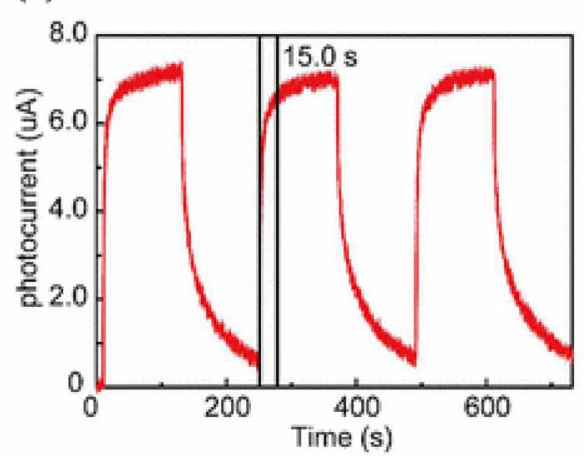

Figure 24. Schematics of a $\mathrm{FeS}_{2}-\mathrm{PbS} / \mathrm{GFET}$ heterojunction and the corresponding charge transfer process before (a) and after (b) the ligand exchange. Photoresponse curves of $\mathrm{FeS}_{2}-\mathrm{PbS} / \mathrm{GFET}$ heterojunction photodetectors on NIR illumination $\left(1100 \mathrm{~nm}, 12 \mu \mathrm{W} / \mathrm{cm}^{2}, V_{\mathrm{DS}}=0.1 \mathrm{~V}\right)$ on/off, before ligand exchange (c) and after (d), (reproduced with permission from Ref. 311, copyright 2017, American Chemical Society).

integrated in modern electronics and related multidisciplinary fields at an exponentially increasing rate. Stretchable electronics, which builds electronic circuits on top of a stretchable substrate or embeds them in a stretchable matrix, enables devices to be deformed into arbitrary shapes while maintaining the performance and reliability of the devices. ${ }^{303,304}$ Flexible electronics have gained considerable research interest in the recent years because of their special features and potential applications in flexible displays, artificial skins, sensors, sustainable energy, etc. With unique geometry, outstanding electronic/optoelectronic properties, excellent mechanical flexibility and good transparency. Flexible electronics fabricated on large area polymeric substrates is an emerging field with a wide range of applications in areas such as displays, health monitoring devices, smart clothing, radio frequency identification devices (RFIDs), and energy storage. ${ }^{305-309}$ Novel printable nanocomposite photosensitizer consisting of colloidal nanocrystals of $\mathrm{FeS}_{2}$ and
$\mathrm{PbS}$ with complementary optical and microstructural properties for broadband photodetection. Using a newly developed ligand exchange to achieve high-efficiency charge transfer across the nanocomposite $\mathrm{FeS}_{2}-\mathrm{PbS}$ sensitizer and graphene on the $\mathrm{FeS}_{2}-\mathrm{PbS}$ /graphene photoconductors, an extraordinary photoresponsivity in exceeding arpound $106 \mathrm{~A} / \mathrm{W}$ was obtained in an ultrabroad spectrum of ultravioletvisible-near-infrared (Fig. 24). ${ }^{310}$ Printable highly conductive cathode interfacial layer (CIL) for efficient polymer solar cells by sensitizing $\mathrm{ZnO}$ nanocrystals with a blue fluorescent conjugated polymer, poly(9,9-bis-(6'-diethoxylphosphorylhexyl) fluorene) was also fabricated. ${ }^{311}$ More recently, to realize green and flexible electronics, ultrastrong, transparent, conductive and printable nanocomposites were successfully prepared by mixing single-walled carbon nanotubes with 2,2,6,6-tetramethylpiperidine-1-oxyl-oxidized cellulose nanofibrils with abundant sodium carboxyl groups on the crystalline nanocellulose surfaces. ${ }^{312}$
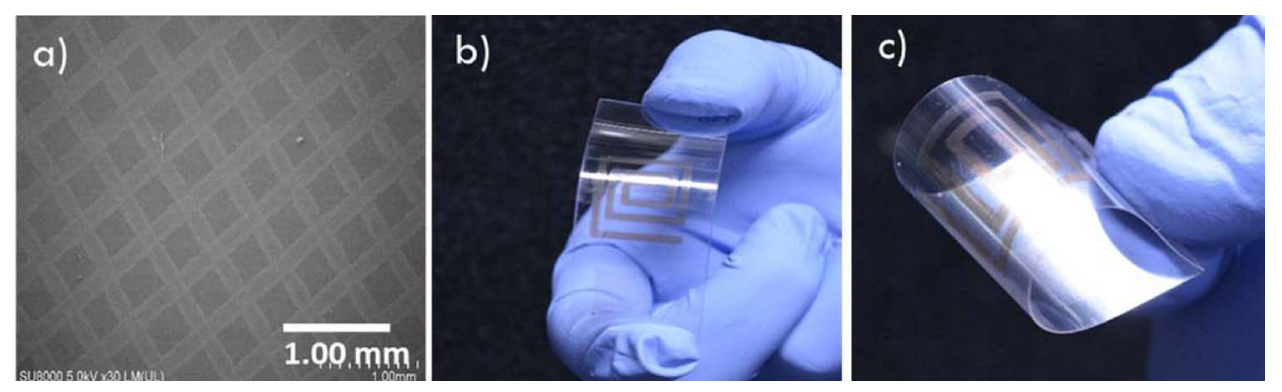

Figure 25. Inkjet printed poly(NVK-co-MAH)-g-P1@Ag nanosphere ink: (a) SEM image of the printed square grids on $\left(1 \times 1 \mathrm{~cm}^{2}\right)$ on glass substrate. Inkjet printed patterns on (b) PET and (c) PVA films, (reproduced with permission from Ref. 305, copyright 2017, Wiley). 
More recently, our group has reported flexible printed patterns of poly(NVK-co-MAH)-g-P1@Ag nanosphere ink on poly(ethylene terephthalate) (PET) and poly(vinyl alcohol) (PVA), respectively. The hybridization with the graft copolymer realized printing of the narrow pattern with the stable ink. Both of the printed patterns showed excellent horizontal electrical conductivity of $8.5 \times 10^{5} \mathrm{~S} \mathrm{~m}^{-1}$ owing to the efficient linkage between the AgNPs on the shell even without annealing or removal of the organic part (Fig. 25). ${ }^{305}$

\section{Summary: Challenges, Opportunities and Outlook}

In this review, we have discussed the significance of organicinorganic hybrid materials within the diverse fields of applications. We have described the recent scientific advances aimed at developing nanoelectronics, drug delivery systems, bioimaging, hybrid solar cells, and the most sought after IoT. Interest in the field of IoT will witness exponential growth over the next decade as markets realize the true potential of real-time data acquisition for various entertainment, knowledge dissemination, defense, environmental, and healthcare applications. Thus, in this review we have summarized the influence of polymers as stabilizers and imparting softness to the hybrid materials, whereas inorganic metal owes mechanical strength, transparency, conductivity, optical properties etc. Controlled and nanosized assemblies of nanomaterials demonstrates strong organic-inorganic interactions. Hybrid materials for optics, biomedical materials, bioimaging, plasmonics, electronics, storage, as we have outlined in our review, have now reached a quite mature stage of development and several products are available on the market. In several applications, such as in integrated devices they have, however, found only a partial success in challenging competing materials, such as organic polymers and purely inorganic materials. Several properties of hybrids are somehow unique, such as the soft-chemistry flexibility that allows a very fine tuning of the material, but represent also a limit. Integration of hybrid materials for new devices is also a clear trend; in this route we can easily forecast a bright future for hybrid materials. Hybrid materials suggests a wealth of potential material, by the nano assemblies of organic-inorganic species. As synthetic methodology advances and becomes more mainstream, exciting new opportunities for materials development in the areas of energy conversion, storage and healthcare may emerge.

\section{ORCID}

Sajjad Husain Mir (D) https://orcid.org/0000-0001-8416-3891

Ajit Khosla (iD https://orcid.org/0000-0002-2803-8532

\section{References}

1. W. Wu, M. Chen, S. Liang, X. Wang, J. Chen, and F. Zhou, J. Colloid Interface Sci., 326, 478 (2008)

2. K. Ramam and M. Lopez, J. Alloys Compd., 466, 398 (2008).

3. S. H. Kim and J. H. Koh, J. Eur. Ceram. Soc., 28, 2969 (2008).

4. M. A. U. Martines, M. R. Davolos, M. J. Júnior, D. F. de Souza, and L. A. O. Nunes, J. Lumin., 128, 1787 (2008).

5. J. M. Saad and P. T. Williams, Energy Fuels, 30(4), 3198 (2016).

6. K. Tsuda, J. Jpn. Petrol. Inst., 50, 240 (2007).

7. H. R. Allcock, Adv. Mater, 6, 106 (1994).

8. B. M. Novak, Adv. Mater, 5, 422 (1993).

9. D. A. Loy and K. J. Shea, Chem. Rev., 95, 1431 (1995).

10. P. Judeinstein and C. Sanchez, J. Mater. Chem., 6, 511 (1996).

11. K. G. Sharp, Adv. Mater, 10, 1243 (1998).

12. C. Sanchez, F. Ribot, and B. Lebeau, J. Mater. Chem., 9, 35 (1999).

13. P. Judeinstein and H. Schmidt, J. Sol. Gel Sci. Technol., 3, 189 (1994)

14. J. H. Harreld, B. Dunn, and J. I. Zink, J. Mater. Chem., 7, 1511 (1997).

15. C. Roscher, R. Buestrich, P. Dannberg, O. Rosch, and M. Popall, Mater. Res. Soc Symp. Proc., 519, 239 (1998).

16. H. K. Kim, S.-J. Kang, S.-K. Choi, Y.-H. Min, and C.-S. Yoon, Chem. Mater, 11, 779 (1999)

17. J. Livage and C. Sanchez, MCLC S\&T Sect. B Nonlinear Opt. Reading, 21, 125 (1999).

18. S. H. Mir and B. Ochiai, ChemistryOpen, 5, 213 (2016)

19. S. H. Mir, K. Ebata, H. Yanagiya, and B. Ochiai, Microsyst. Tech., 24, 605 (2018).
20. S. Dire, F. Babonneau, C. Sanchez, and J. Livage, J. Mater. Chem., 2, 239 (1992)

21. N. I. Koslova, B. Viana, and C. Sanchez, J. Mater. Chem., 3, 111 (1993).

22. S. M. Jones, L. Kotorman, and S. E. Friberg, J. Mater. Sci., 31, 1475 (1996)

23. E. Cordoncillo, B. Viana, P. Escribano, and C. Sanchez, J. Mater. Chem., 8, 507 (1998).

24. V. de Zea Bermudez, L. D. Carlos, M. C. Duarte, M. M. Silva, C. J. R. Silva, M. J. Smith, M. Assuncao, and L. Alcacer, J. Alloys Compd., 21, 275 (1998).

25. T. Dantas de Morais, F. Chaput, K. Lahlil, and J.-P. Boilot, Adv. Mater, 11, 107 (1999).

26. T. Fujinami, K. Sugie, K. Mori, and M. A. Mehta, Chem. Lett., 7, 619 (1998).

27. L. Depre, J. Kappel, and M. Popall, Electrochim. Acta, 43, 1301 (1998).

28. I. Honma, Y. Takeda, and J. M. Bae, Solid State Ionics, 120, 255 (1999).

29. P. Hernan, C. Del Pino, and E. Ruiz-Hitzky, Chem. Mater, 4, 49 (1992)

30. S. H. Mir and B. Ochiai, J. Electrochem. Soc., 165(8), B3030 (2018).

31. M. Barboiu, C. Luca, C. Guizard, N. Hovnanian, L. Cot, and G. Popescu, J. Membr. Sci., 129, 197 (1997).

32. S. H. Mir and B. Ochiai, Macromol. Mater. Eng., 301, 1026 (2016).

33. P. Battioni, E. Cardin, M. Louloudi, B. Schollhorn, G. A. Spyroulias, D. Mansuy, and T. G. Traylor, Chem. Commun., 17, 2037 (1996)

34. M. Buechler-Skoda, R. Gill, D. Vu, C. Nguyen, and G. Larsen, Appl. Catal. A, 2, 185 (1999).

35. K. J. Ciuffi, H. C. Sacco, J. B. Valim, C. M. C. P. Manso, O. A. Serra, O. R. Nascimento, E. A. Vidoto, and Y. Iamamoto, J. Non-Cryst. Solids, 247, 146 (1999).

36. M. T. Reetz, Adv. Mater, 9, 943 (1997).

37. B. Wang, B. Li, Q. Deng, and S. Dong, Anal. Chem., 70, 3170 (1998).

38. J. D. Brennan, J. S. Hartman, E. I. Ilnicki, and M. Rakic, Chem. Mater, 11, 1853 (1999).

39. G. J. Owens, R. K. Singh, F. Foroutan, M. Alqaysi, C.-M. Han, C. Mahapatra, H.-W. Kim, and J. C. Knowles, Prog. Mater. Sci., 77, 1 (2016).

40. J. R. McCarthy and R. Weissleder, Adv. Drug Deliv. Rev., 60, 1241 (2008).

41. M. Groenewolt, Progr. Org. Coat., 61, 106 (2008).

42. E. Amerio, P. Fabbri, G. Malucelli, M. Messori, M. Sangermano, and R. Taurino, Prog. Org. Coat., 62, 129 (2008)

43. L. Y. L. Wu, E. Chwa, Z. Chen, and X. T. Zeng, Thin Solid Films, 516, 1056 (2008).

44. S. Nagayama and B. Ochiai, Polym. J., 48, 1059 (2016).

45. B. Ochiai and H. Konta, Molecules, 20, 15049 (2015).

46. B. Ochiai and H. Konta, Nanoscale Res. Lett., 8, 373 (2013).

47. F. D.-Matteis, P. Prosposito, F. Sarcinelli, M. Casalboni, R. Pizzoferrato, A. Furlani, M. V. Russo, A. Vannucci, and M. Varasi, J. Non-Cryst. Solids, 245, 15 (1999).

48. E. P. Ng and S. Mintova, Microporous Mesoporous Mater., 114, 1 (2008).

49. L. Xu and H. K. Lee, J. Chromatogr. A, 1195, 78 (2008).

50. Y. Guo, A. Mylonakis, Z. Zhang, G. Yang, P. I. Lelkes, S. Che, Q. Lu, and Y. Wei, Chem. A Eur. J., 14, 2909 (2008)

51. J. Gun and O. Lev, Anal. Chim. Acta., 336, 1 (1996).

52. C. O. Avellaneda, K. Dahmouche, L. O. S. Bulhoes, and A. Pawlicka, J. Sol-Gel. Sci. Technol., 19, 447 (2000).

53. J. Fei, K. G. Lim, and G. T. R. Palmore, Chem. Mater, 20, 3832 (2008).

54. N. Ozer and J. P. Cronin, Key Eng. Mater, 264(I), 337 (2004)

55. H. Yang and Y. Zhu, Biosens. Bioelectron., 22, 2989 (2007).

56. Z. Fang, S. Wang, L. Zhao, B. Dong, Z. Xu, J. Ren, and Q. Yang, Mater. Lett., 62, 1514 (2008).

57. T. Itoh, I. Matsubara, W. Shin, and N. Izu, Mater. Lett., 61, 4031 (2007).

58. Y. Zhang, L. Shan, Z. Tu, and Y. Zhang, Sep. Purif. Technol., 63, 207 (2008).

59. S. E. Nam, S. O. Kim, Y. Kang, J. W. Lee, and K. H. Lee, J. Membr. Sci., 322, 466 (2008).

60. E. Landi, S. Martorana, A. Tampieri, S. Guicciardi, and C. Melandri, Key Eng. Mater, 361547 (2008).

61. M. Darder, P. Aranda, and E. Ruiz-Hitzky, Adv. Mater, 19, 1309 (2007).

62. X. C. Tan, Y. X. Tian, P. X. Cai, and X. Y. Zou, Anal. Bioanal. Chem., 381, 500 (2005).

63. J. S. Miller, Adv. Mater, 5, 587 (1993).

64. J. S. Miller, Adv. Mater, 5, 671 (1993).

65. G. P. Evans, Advances in Electrochemical Science and Engineering, Vol. 1 (Eds: H. Gerischer and C. W. Tobias,), VCH, Weinheim 1990, p.1.

66. P. Baeuerle, Adv. Mater, 5, 879 (1993).

67. A. O. Patil, A. J. Heeger, and F. Wudl, Chem. Rev., 88, 183 (1988).

68. S. Roth and M. Filzmoser, Adv. Mater, 2, 356 (1990).

69. M. J. Sailor and C. L. Curtis, Adv. Mater, 6, 688 (1994).

70. P. Novak, K. Mueller, K. S. V. Santhanam, and O. Haas, Chem. Rev., 97, 207 (1997)

71. R. D. McCullough, Adv. Mater, 10, 93 (1998).

72. P. Judeinstein and C. Sanchez, J. Mater. Chem., 6, 511 (1996).

73. C. Sanchez, G. J. A. A. Soler-Illia, F. Ribot, and D. Grosso, C. R. Chimie., 6, 1131 (2003).

74. C. Sanchez, G. J. A. A. Soler-Illia, F. Ribot, T. Lalot, C. R. Mayer, and V. Cabuil, Chem. Mater, 13, 3061 (2001).

75. G. J. A. A. Soler-Illia, C. Sanchez, B. Lebeau, and J. Patarin, Chem. Rev., 102, 4093 (2002).

76. G. A. Ozin, Chem. Commun., 419 (2000)

77. D. J. Tranchemontagne, J. L. Mendoza-Cortes, M. O'Keeffe, and O. M. Yaghi, Chem. Soc. Rev., 38, 1257 (2009).

78. S. C. Warren, L. C. Messina, L. S. Slaughter, M. Kamperman, Q. Zhou, S. M. Gruner, F. J. DiSalvo, and U. Wiesner, Science, 320, 1748 (2008).

79. L. Nicole, L. Rozes, and C. Sanchez, Adv. Mater., 2, 3208 (2010). 
80. C. T. Kresge, M. E. Leonowicz, W. J. Roth, J. C. Vartuli, and J. S. Beck, Nature, 359, 710 (1992).

81. F. Hoffmann, M. Cornelius, J. Morell, and M. Fröba, Angew. Chem. Int. Ed., 45 3216 (2006).

82. J. Alauzun, A. Mehdi, C. Reye, and R. J. P. Corriu, J. Mater. Chem., 17, 349 (2007)

83. R. Backov, Soft Matter., 2, 452 (2006).

84. U. H. F. Bunz, Adv. Mater., 18, 973 (2006).

85. E. Ruiz Hitzky, K. Ariga, and Y. M. Lvov, Bio-inorganic Hybrid Nanomaterials, Wiley-VCH, Weinheim, Germany 2008.

86. M. Vallet-Regi and D. Arcos, Biomimetic Nanoceramics in Clinical Use, Royal Society of Chemistry, Cambridge, UK 2008.

87. R. Gangopadhyay and A. De, Chem. Mater, 12, 608 (2000).

88. C. C. Chen, C. S. C.Bose, and K. Rajeshwar, J. Electroanal. Chem., 350, 161 (1993),

89. M. Hasik, A. Drelinkiewicz, M. Choczynski, S. Quillard, and A. Pron, Synth. Met., 84, 93 (1997).

90. H.-S. Li, M. Josowicz, D. R. Baer, M. H. Engelhard, and J. Janata, J. Electrochem. Soc., 142, 798 (1995).

91. K. Rajeshwar, C. S. C. Bose, and US , 5, 334292 (1994)

92. W. A. Wampler, C. Wei, and K. Rajeshwar, J. Electrochem. Soc., 141(2), L13 (1994).

93. S. Holdcroft and B. L. Funt, J. Electroanal. Chem. Interfacial. Electrochem., 240 89 (1988).

94. C. S. C. Bose and K. Rajeshwar, J. Electroanal. Chem., 333, 235 (1992).

95. G. Bidan, O. Jarjayes, J. M. Fruchart, and E. Hannecart, Adv. Mater., 6, 152 (1994)

96. M. Wan, W. Zhou, and J. Li, Synth. Met., 78, 27 (1996).

97. H. Yoneyama, A. Kishimoto, and S. Kuwabata, Chem. Commun., 15, 986 (1991).

98. H. Yoneyama and Japanese Pat. JP 04136195 A2, (1992).

99. C.-L. Huang, R. E. Partch, and E. Matijevic, J. Colloid Interface Sci., 170, 275 (1995).

100. M. Matsumura, T. Ohno, S. Saito, and M. Ochi, Chem. Mater, 8, 1370 (1996).

101. K. Murakoshi, R. Kogure, Y. Wada, and S. Yanagida, Chem. Lett., 5, 471 (1997)

102. M. Matsumura and T. Ohno, Adv. Mater., 9, 357 (1997).

103. B. P. Jelle, G. Hagen, and S. Noedland, Electrochim. Acta, 38, 1497 (1993)

104. N. R. Avvaru, N. R. de Tacconi, and K. Rajeshwar, Analyst, 123, 113 (1998).

105. S. Maeda and S. P. Armes, Chem. Mater, 7, 171 (1995).

106. M. D. Butterworth, R. Corradi, J. Johal, S. F. Sascelles, S. Maeda, and S. P. Armes, J. Colloid Interface Sci., 174, 510 (1995).

107. M. Lal, M. Joshi, D. N. Kumar, C. S. Friend, J. Winiarz, T. Asefa, K. Kim, and P. N. Prasad, Mater. Res. Soc. Symp. Proc., 519, 217 (1998).

108. P. Chartier, H. Nguyen Cong, and C. Sene, Sol. Energy Mater. Sol. Cells, 52, 413 (1998).

109. R. L. Johnston, Atomic \& Molecular Clusters, Taylor \& Francis, London (2002).

110. U. Kreibig and M. Vollmer, Optical Properties of Metal Clusters, Springer, Berlin (1995).

111. M.-C. Daniel and D. Astruc, Chem. Rev., 104, 293 (2004).

112. M. G.Warner and J. E. Hutchison, in Synthesis, Functionalization and Surface Treatment of Nanoparticles, ed. M.-I. Baraton, American Scientific Publishers, California, 2003, p. 67.

113. K. L. Genson, J. Holzmueller, C. Jiang, J. Xu, J. D. Gibson, E. R. Zubarev, and V. V. Tsukruk, Langmuir, 22, 7011 (2006).

114. E. R. Zubarev, J. Xu, A. Sayyad, and J. D. Gibson, J. Am. Chem. Soc., 128, 4958 (2006).

115. C. M. Intelmann, H. Dietz, and W. Plieth, Eur. J. Inorg. Chem., 3711 (2005).

116. S. H. Cho and S.-M. Park, J. Phys. Chem. B, 110, 25656 (2006).

117. P. Englebienne and A. V. Hoonacker, J. Colloid Interface Sci., 292, 445 (2005).

118. E. Dulkeith, M. Ringler, T. A. Klar, J. Feldmann, A. M. Javier, and W. J. Parak, Nano Lett., 5, 585 (2005).

119. G. Schneider and G. Decher, Nano Lett., 6, 530 (2006).

120. R. Gangopadhyay and A. De, Chem. Mater, 12, 2064 (2000).

121. C. O. Oriakhi, J. Chem. Educ., 77, 1138 (2000).

122. S. R. Forrest, Nature, 428, 911 (2004).

123. A. L. Rogach, D. V. Talapin, and H. Weller, Colloids and Colloid Assemblies, ed. F. Caruso, Wiley-VCH, Weinheim, 2004, pp. 52.

124. A. L. Rogach, A. Eychmu“" ller, S. G. Hickey, and S. V. Kershaw, Small, 3, 536 (2007).

125. B. O. Dabbousi, J. Rodriguez-Viejo, F. V. Mikulec, J. R. Heine, H. Mattoussi, R. Ober, K. F. Jensen, and M. G. Bawendi, J. Phys. Chem. B, 101, 9463 (1997).

126. X. Peng, M. C. Schlamp, A. V. Kadavanich, and A. P. Alivisatos, J. Am. Chem. Soc., 119, 7019 (1997).

127. M. J. MacLachlan, I. Manners, and G. A. Ozin, Adv. Mater, 12, 675 (2000).

128. D. Yu, C. Wang, and P. Guyot-Sionnest, Science, 300, 1277 (2003).

129. J. H. Burroughes, D. D. C. Bradley, A. R. Brown, R. N. Marks, K. Mackay, R. H. Friend, P. L. Burns, and A. B. Holmes, Nature, 347, 539 (1990).

130. C. A. Leatherdale, C. R. Kagan, N. Y. Morgan, S. A. Empedocles, M. A. Kastner, and M. G. Bawendi, Phys. Rev. B, 62, 2669 (2000).

131. E. Holder, B. M. W. Langeveld, and U. S. Schubert, Adv. Mater, 17, 1109 (2005).

132. H. V. Demir, S. Nizamoglu, T. Ozel, E. Mutlugun, I. O. Huyal, E. Sari, E. Holder, and N. Tian, New J. Phys., 9, 362 (2007)

133. L. Bakueva, S. Musikhin, M. A. Hines, T. W. F. Chang, M. Tzolov, G. D. Scholes, and E. H. Sargent, Appl. Phys. Lett., 82, 2895 (2003).

134. J. H. Warner, A. R. Watt, E. Thomsen, N. Heckenberg, P. Meredith, and H. Rubinsztein-Dunlop, J. Phys. Chem. B, 109, 9001 (2005).

135. M. Anni, L. Manna, R. Cingolani, D. Valerini, A. Creti, and M. Lomascolo, Appl. Phys. Lett., 85, 4169 (2004).
136. N. C. Greenham, X. G. Peng, and A. P. Alivisatos, Phys. Rev. B: Condens. Matter, 54, 17628 (1996).

137. S. A. McDonald, G. Konstantatos, S. G. Zhang, P. W. Cyr, E. J. D. Klem, L. Levina, and E. H. Sargent, Nat. Mater, 4, 138 (2005).

138. G. Konstantatos, C. Huang, L. Levina, Z. Lu, and E. H. Sargent, Adv. Funct. Mater, 15, 1865 (2005).

139. S. Zhang, P. W. Cyr, S. A. McDonald, G. Konstantatos, and E. H. Sargent, Appl. Phys. Lett., 87, 233101 (2005).

140. O. Solomeshch, A. Kigel, A. Saschiuk, V. Medvedev, A. Aharoni, A. Razin, Y. Eichen, U. Banin, E. Lifshitz, and N. Tessler, J. Appl. Phys., 98, 074310 (2005).

141. D. S. Ginger and N. C. Greenham, Synth. Met., 101, 425 (1999).

142. D. S. Ginger and N. C. Greenham, Phys. Rev. B: Condens. Matter Mater. Phys., 59, 10622 (1999).

143. D. S. Koktysh, N. Gaponik, M. Reufer, J. Crewett, U. Scherf, A. Eychmu“ ller, J. M. Lupton, A. L. Rogach, and J. Feldmann, Chem. Phys. Chem., 5, 1435 (2004).

144. Y. Li, A. Rizzo, M. Mazzeo, L. Carbone, L. Manna, R. Cingolani, and G. Gigli, J. Appl. Phys., 97, 113501 (2005).

145. N. Tessler, V. Medvedev, M. Kazes, S. H. Kan, and U. Banin, Science, 295, 1506 (2002).

146. B. T. Nguyen, J. E. Gautrot, C. Ji, P.-L. Brunner, M. T. Nguyen, and X. X. Zhu, Langmuir, 22, 4799 (2006).

147. E. Arici, D. Meissner, and N. S. Sariciftci, Encyclopedia of Nanoscience and Nanotechnology, ed. H. S. Nalwa, American Scientific Publishers, Valencia, CA, 2004, vol. 3, pp. 929

148. N. C. Greenham, X. Peng, and A. P. Alivisatos, Phys. Rev. B: Condens. Matter, 54, 17628 (1996).

149. B. Sun and N. C. Greenham, Phys. Chem. Chem. Phys., 8, 3557 (2006).

150. W. U. Huynh, X. Peng, and A. P. Alivisatos, Adv. Mater., 11, 923 (1999)

151. A. Maria, P. W. Cyr, E. J. D. Klem, L. Levina, and E. H. Sargent, Appl. Phys. Lett., 87, 213112 (2005)

152. P. Wang, A. Abrusci, H. M. P. Wong, M. Svensson, M. R. Andersson, and N. C. Greenham, Nano Lett., 6, 1789 (2006).

153. M. Y. Odoi, N. I. Hammer, K. Sill, T. Emrick, and M. D. Barnes, J. Am. Chem. Soc., 128, 3506 (2006)

154. D. J. Milliron, A. P. Alivisatos, C. Pitois, C. Edder, and J. M. J. Frechet, Adv. Mater, 15, 58 (2003).

155. C. Querner, A. Benedetto, R. Demadrille, P. Rannou, and P. Reiss, Chem. Mater, 18, 4817 (2006).

156. C.-H. Chou, H.-S. Wang, K.-H. Wei, and J. Y. Huang, Adv. Funct. Mater, 6, 909 (2006).

157. R. C. Advincula, Dalton Trans., 2778 (2006).

158. J. Locklin, D. Patton, S. Deng, A. Baba, M. Millan, and R. C. Advincula, Chem. Mater, 16, 5187 (2004).

159. A. Javier, C. S. Yun, J. Sorena, and G. F. Strouse, J. Phys. Chem. B, 107, 435 (2003).

160. R. van Beek, A. P. Zoombelt, L. W. Jenneskens, C. A. van Walree, C. D. M. Donegla, D. Veldman, and R. A. J. Janssen, Chem. Eur. J., 12, 8075 (2006).

161. D. J. de Aberasturi, A. B. Serrano-Montes, and L. M. Liz-Marzan, Adv. Opt. Mater. 3, 602 (2015).

162. J. R. Lakowicz, Plasmonics, 1, 5 (2006).

163. A. Lauchner, A. E. Schlather, A. Manjavacas, Y. Cui, M. J. McClain, G. J. Stec, F. J. G. de Abajo, P. Nordlander, and N. J. Halas, Nano Lett., 15, 6208 (2015).

164. Y. B. Zheng, B. Kiraly, P. S. Weiss, and T. J. Huang, Nanomedicine, 7, 751 (2012).

165. A. Guerrero-Martinez, M. Grzelczak, and L. M. Liz-Marzan, ACS Nano, 6, 3655 (2012).

166. L. M. Liz-Marzan, J. Phys. Chem. Lett., 4, 1197 (2013).

167. M. Kauranen and A. V. Zayats, Nat. Photonics, 6, 737 (2012).

168. E. C. Dreaden, A. M. Alkilany, X. H. Huang, C. J. Murphy, and M. A. El-Sayed, Chem. Soc. Rev., 41, 2740 (2012).

169. M. C. Daniel and D. Astruc, Chem. Rev., 104, 293 (2004)

170. P. X. Zhao, N. Li, and D. Astruc, Coord. Chem. Rev., 257, 638 (2013).

171. P. K. Jain, X. H. Huang, I. H. El-Sayed, and M. A. El-Sayed, Acc. Chem. Res., 41, 1578 (2008)

172. S. W. Zeng, D. Baillargeat, H. P. Ho, and K. T. Yong, Chem. Soc. Rev., 43, 3426 (2014).

173. D. A. Giljohann, D. S. Seferos, W. L. Daniel, M. D. Massich, P. C. Patel, and C. A. Mirkin, Angew. Chem. Int. Ed., 49, 3280 (2010).

174. M. Bauch, K. Toma, M. Toma, Q. Zhang, and J. Dostalek, Plasmonics, 9, 781 (2013).

175. J. A. Webb and R. Bardhan, Nanoscale, 6, 2502 (2014)

176. T. K. Sau, A. L. Rogach, F. Jackel, T. A. Klar, and J. Feldmann, Adv. Mater, 22, 1805 (2010)

177. J. R. Lakowicz, K. Ray, M. Chowdhury, H. Szmacinski, Y. Fu, J. Zhang, and K. Nowaczyk, Analyst, 133, 1308 (2008).

178. P. K. Jain, K. S. Lee, I. H. El-Sayed, and M. A. El-Sayed, J. Phys. Chem. B, 110, 7238 (2006)

179. S. Lal, S. Link, and N. J. Halas, Nat. Photonics, 1, 641 (2007).

180. M. C. Daniel and D. Astruc, Chem. Rev., 104, 293 (2004).

181. Y. K. Xu, S. Hwang, S. Kim, and J. Y. Chen, ACS Appl. Mater. Interfaces, 6, 5619 (2014).

182. J. R. Navarro, F. Lerouge, C. Cepraga, G. Micouin, A. Favier, D. Chateau, M. T. Charreyre, P. H. Lanoe, C. Monnereau, F. Chaput, S. Marotte, Y. Leverrier, J. Marvel, K. Kamada, C. Andraud, P. L. Baldeck, and S. Parola, Biomaterials, 34, 8344 (2013) 
183. J. R. Navarro, F. Lerouge, G. Micouin, C. Cepraga, A. Favier, M. T. Charreyre, N. P. Blanchard, J. Lerme, F. Chaput, M. Focsan, K. Kamada, P. L. Baldeck, and S. Parola, Nanoscale, 6, 5138 (2014).

184. Z. Jiang, B. Dong, B. Chen, J. Wang, L. Xu, S. Zhang, and H. Song, Small, 9, 604 (2013).

185. P. Huang, J. Lin, S. Wang, Z. Zhou, Z. Li, Z. Wang, C. Zhang, X. Yue, G. Niu, M. Yang, D. Cui, and X. Chen, Biomaterials, 34, 4643 (2013).

186. T. Zhao, K. Yu, L. Li, T. Zhang, Z. Guan, N. Gao, P. Yuan, S. Li, S. Q. Yao, Q. H. Xu, and G. Q. Xu, ACS Appl. Mater. Interfaces, 6, 2700 (2014).

187. N. S. Abadeer, M. R. Brennan, W. L. Wilson, and C. J. Murphy, ACS Nano, 8, 8392 (2014).

188. X. Ke, D. Wang, C. Chen, A. Yang, Y. Han, L. Ren, D. Li, and H. Wang, Nanoscale Res. Lett., 9, 2492 (2014).

189. Z. Bai, R. Chen, P. Si, Y. Huang, H. Sun, and D. H. Kim, ACS Appl. Mater. Interfaces, 5, 5856 (2013).

190. Y. Pang, Z. Rong, J. Wang, R. Xiao, and S. Wang, Biosens. Bioelectron., 66, 527 (2015).

191. N. Niu, F. He, P. Ma, S. Gai, G. Yang, F. Qu, Y. Wang, J. Xu, and P. Yang, ACS Appl. Mater. Interfaces, 6, 3250 (2014).

192. G. Terentyuk, E. Panfi lova, V. Khanadeev, D. Chumakov, E. Genina, A. Bashkatov, V. Tuchin, A. Bucharskaya, G. Maslyakova, N. Khlebtsov, and B. Khlebtsov, Nano Res., 7, 325 (2014).

193. Y. Li, T. Wen, R. Zhao, X. Liu, T. Ji, H. Wang, X. Shi, J. Shi, J. Wei, Y. Zhao, X. Wu, and G. Nie, ACS Nano, 8, 11529 (2014).

194. M. A. Noginov, G. Zhu, A. M. Belgrave, R. Bakker, V. M. Shalaev, E. E. Narimanov, S. Stout, E. Herz, T. Suteewong, and U. Wiesner, Nature, $\mathbf{4 6 0}$, 1110 (2009)

195. K. Cho, X. Wang, S. Nie, Z. Chen, and D. M. Shin, Clin. Cancer Res., 14, 1310 (2008).

196. M. E. Davis, Z. Chen, and D. M. Shin, Nat. Rev. Drug Discovery, 7, 771 (2008).

197. D. Peer, J. M. Karp, S. Hong, O. C. Farokhzad, R. Margalit, and R. Langer, Nat. Nanotechnol., 2, 751 (2007).

198. S. Laurent, D. Forge, M. Port, A. Roch, L. Vander Elst, and R. N. Nuller, Chem Rev., 108, 2064 (2008).

199. M. Ferrari, Nat. Rev. Cancer, 5, 161 (2005).

200. F. Alexis, E. Pridgen, L. K. Molnar, and O. C. Farokhzad, Mol. Pharmaceutics, 5, 505 (2008).

201. S. D. Li and L. Huang, Mol. Pharmaceutics, 5, 496 (2008).

202. V. P. Torchilin, Nat. Rev. Drug Discovery, 4, 145 (2005).

203. A. M. Smith, H. Duan, A. M. Mohs, and S. Nie, Adv. Drug Delivery Rev., 60, 1226 (2008).

204. W. W. Yu, E. Chang, R. Drezek, and V. L. Colvin, Biochem. Biophys. Res. Commun., 348, 781 (2006).

205. J. Weng and J. Ren, Curr. Med. Chem., 13, 897 (2006).

206. H. Zhang, D. Yee, and C. Wang, Nanomedicine, 3, 83 (2008).

207. V. Biju, T. Itoh, A. Anas, A. Sujith, and M. Ishikawa, Anal. Bioanal. Chem., 391, 2469 (2008)

208. M. S. Yavuz, Y. Cheng, J. Chen, C. M. Cobley, Q. Zhang, M. Rycenga, J. Xie, C. Kim, K. H. Song, A. G. Schwartz, L. V. Wang, and Y. Xia, Nat. Mater, 8, 935 (2009).

209. M. Hu, J. Chen, Z. Y. Li, L. Au, G. V. Hartland, X. Li, M. Marquez, and Y. Xia, Chem. Soc. Rev., 35, 1084 (2006)

210. P. K. Jain, X. Huang, I. H. El-Sayed, and E.-S. M. A. , Acc. Chem. Res., 41, 1578 (2008).

211. E. Boisselier and D. Astruc, Chem. Soc. Rev., 38, 1759 (2009).

212. R. P. Bagwe, C. Yang, L. R. Hilliard, and W. Tan, Langmuir, 20, 8336 (2004).

213. D. Ma, J. Guan, F. Normandin, S. De'nomme'e, G. Enright, T. Veres, and B. Simard, Chem. Mater, 18, 1920 (2006).

214. J. L. Bridot, A. C. Faure, S. Laurent, C. Rivire, C. Billotey, B. Hiba, M. Janier, V. Josserand, J. L. Coll, L. Vander Elst, R. Muller, S. Roux, P. Perriat, and O. Tillement, J. Am. Chem. Soc., 129, 5076 (2007).

215. O. R. Evans and W. Lin, Acc. Chem. Res., 35, 511 (2002).

216. L. Ma, C. Abney, and W. Lin, Chem. Soc. Rev., 38, 1248 (2009).

217. J. L. C. Rowsell and O. M. Yaghi, Angew. Chem., Int. Ed., 44, 4670 (2005).

218. D. Mircea and J. R. Long, Angew. Chem., Int. Ed., 47, 6766 (2008).

219. B. Chen, L. Wang, Y. Xio, F. R. Fronczek, M. Xue, Y. Cui, and G. Qian, Angew. Chem., Int. Ed., 48, 500 (2009).

220. W. Lin, W. J. Rieter, and K. M. L. Taylor, Angew. Chem., Int. Ed., 48, 650 (2009).

221. P. Horcajada, T. Chalati, C. Serre, B. Gillet, C. Sebrie, T. Baati, J. F. Eubank, D. Heurtaux, P. Clayette, C. Kreuz, J. S. Chang, Y. K. Hwang, V. Marsaud, P. N. Bories, L. Cynober, S. Gil, G. Ferey, P. Couvreur, and R. Gref, Nat. Mater, 9 , $172(2010)$.

222. M. D. Rowe, D. H. Thamm, S. L. Kraft, and S. G. Boyes, Biomacromolecules, 10 983 (2009).

223. W. J. Rieter, K. M. L. Taylor, H. An, W. Lin, and W. Lin, J. Am. Chem. Soc., 128 , $9024(2006)$

224. S. Santra, H. Yang, D. Dutta, J. T. Stanley, P. H. Holloway, W. Tan, B. M. Moudgil, and R. A. Mericle, Chem. Commun., 2810 (2004).

225. J. S. Kim, W. J. Rieter, K. M. L. Taylor, H. An, W. Lin, and W. Lin, J. Am. Chem. Soc., 129, 8962 (2007).

226. R. Kumar, I. Roy, T. Y. Ohulchanskyy, L. N. Goswami, A. C. Bonoiu, E. J. Bergey, K. M. Tramposch, A. Maitra, and P. N. Prasad, ACS Nano, 2, 449 (2008).

227. J. Qian, X. Li, M. Wei, X. Gao, Z. Xu, and S. He, Opt. Express, 16, 19568 (2008).
228. S. Kim, T. Y. Ohulchanskyy, H. E. Pudavar, R. K. Pandey, and P. N. Prasad, J. Am. Chem. Soc., 129, 2669 (2007).

229. C. Y. Lai, B. G. Trewyn, D. M. Jeftinija, K. Jeftinija, S. Xu, S. Jeftinija, and V. S. Y. Lin, J. Am. Chem. Soc., 125, 4451 (2003).

230. S. Giri, B. G. Trewyn, M. P. Stellmaker, and V. S. Y. Lin, Angew. Chem., Int. Ed., 44, 5038 (2005).

231. J. L. Vivero-Escoto, I. I. Slowing, C. W. Wu, and V. S. Y. Lin, J. Am. Chem. Soc., 131, 3462 (2009)

232. Y. Zhao, B. G. Trewyn, I. Slowing, and V. S. Y. Lin, J. Am. Chem. Soc., 131, 8398 (2009)

233. R. Liu, X. Zhao, T. Wu, and P. Feng, J. Am. Chem. Soc., 130, 14418 (2008),

234. J. Lu, E. Choi, F. Tamanoi, and J. I. Zink, Small, 4, 421 (2008).

235. C. L. Zhu, X. Y. Song, W. H. Zhou, H. H. Yang, Y. H. Wen, and X. R. Wang, J. Mater. Chem., 19, 7765 (2009)

236. T. Sakata, K. Hashimoto, and M. Hiramoto, J. Phys. Chem., 94, 3040 (1990)

237. J. Takada, H. Awaji, M. Koshioka, A. Nakajima, and W. A. Nevin, Appl. Phys. Lett., 61, 2184 (1992).

238. T. Miyasaka, T. Watanabe, A. Fujishima, and K. Honda, J. Am. Chem. Soc., 100 6657 (1978).

239. X. Hong, T. Ishihara, and A. V. Nurmikko, Phys. Rev. B, 45, 6961 (1992).

240. J. Y. Kim, K. Lee, N.E. Coates, D. Moses, T.-Q. Nguyen, M. Dante, and A. J. Heeger, Science, 317, 222 (2007).

241. L. Zhao and Z. Lin, Adv. Mater, 24, 4353 (2012).

242. G. Li, V. Shrotriya, J. S. Huang, Y. Yao, T. Moriarty, K. Emery, and Y. Yang, Nat. Mater, 4, 864 (2005).

243. M. C. Scharber, D. Wuhlbacher, M. Koppe, P. Denk, C. Waldauf, A. J. Heeger, and C. L. Brabec, Adv. Mater, 18, 789 (2006).

244. H. Hoppe and N. S. Sariciftci, J. Mater. Chem., 16, 45 (2006)..

245. S. H. Park, A. Roy, S. Beaupre, S. Cho, N. Coates, J. S. Moon, D. Moses, M. Leclerc, K. Lee, and A. J. Heeger, Nat. Photon., 3, 297 (2009).

246. J. Xu, J. Xia, and Z. Q. Lin, Angew. Chem. Int. Ed., 46, 1860 (2007)

247. V. L. Colvin, M. C. Schlamp, and A. P. Alivisatos, Nature, 370, 354 (1994).

248. V. I. Klimov, A. A. Mikhailovsky, S. Xu, A. Malko, J. A. Hollingsworth, C. A. Leatherdale, H. J. Eisler, and M. G. Bawendi, Science, 290, 314 (2000).

249. W. C. W. Chan and S. Nie, Science, 281, 2016 (1998).

250. A. P. Alivisatos, Nat. Biotechnol., 22, 47 (2004).

251. D. Yu, C. Wang, and P. Guyot-Sionnest, Science, 300, 1277 (2003).

252. B. Walker, A. B. Tamayo, X.-D. Dang, P. Zalar, J. H. Seo, A. Garcia, M. Tantiwiwat, and T.-Q. Nguyen, Adv. Funct. Mater, 19, 3063 (2009).

253. Y. Sun, G. C. Welch, W. L. Leong, C. J. Takacs, G. C. Bazan, and A. J. Heeger, Nat. Mater, 11, 44 (2012).

254. K. A Parrey, A. Aziz, S. G. Ansari, S. H. Mir, A. Khosla, and A. Niazi, J. Electrochem. Soc., 165(8), B3023 (2018).

255. G. Li, V. Shrotriya, J. S. Huang, Y. Yao, T. Moriarty, K. Emery, and Y. Yang, Nat. Mater, 4, 864 (2005)

256. J. L. Wu, F. C. Chen, Y. S. Hsiao, F. C. Chien, P. Chen, C. H. Kuo, M. H. Huang, and C. S. Hsu, ACS Nano, 5, 959 (2011).

257. X. Fan, M. Zhang, X. Wang, F. Yang, and X. Meng, J. Mater. Chem. A, 1, 8694 (2013).

258. B. R. Saunders, J. Colloid Interface Sci., 369, 1 (2012)

259. J. Chandrasekaran, D. Nithyaprakash, K. B. Ajjan, S. Maruthamuthu, D. Manoharan, and S. Kumar, Renewable Sustainable Energy Rev., 15, 1228 (2011).

260. M. Skompska, Synth. Met., 160, 1 (2010)

261. B. R. Saunders and M. L. Turner, Adv. Colloid Interface Sci., 138, 1 (2008).

262. E. Holder, N. Tessler, and A. L. Rogach, J. Mater. Chem., 18, 1064 (2008).

263. P. Reiss, E. Couderc, J. De Girolamo, and A. Pron, Nanoscale, 3, 446 (2011).

264. A. A. Damitha, T. Adikaari, D. M. Nanditha, M. Dissanayake, S. Ravi, and P. Silva, IEEE J. Sel. Top. Quantum Electron., 16, 1595 (2010).

265. S. Kumar and G. D. Scholes, Microchim. Acta, 160, 315 (2007)

266. J. Boucle, P. Ravirajan, and J. Nelson, J. Mater. Chem., 17, 3141 (2007).

267. S. Guenes and N. S. Saricici, Inorg. Chim. Acta, 361, 581 (2008).

268. L. Li, T. Zhai, H. Zeng, X. Fang, Y. Bando, and D. Golberg, J. Mater. Chem., 21, 40 (2011)

269. M. Yu, Y. Z. Long, B. Sun, and Z. Fan, Nanoscale, 4, 2783 (2012).

270. M. D. McGehee, MRS Bull., 34, 95 (2011).

271. W. Lu and C. M. Lieber, Nat. Mater, 6, 841 (2007).

272. L. P. Ma, J. Liu, and Y. Yang, Appl. Phys. Lett., 80, 2997 (2002).

273. K. H. Lee, H. Lee, K. Lee, M. S. Oh, S. Im, and S. M. Yoon, Adv. Mater, 21, 4287 (2009)

274. Y. Kuang, R. Huang, Y. Tang, W. Ding, L. Zhang, and Y. Wang, IEEE Elec. Dev. Lett., 31, 758 (2010).

275. F. Li, D. Son, S. Seo, H. Cha, H. Kim, B. Kim, J. H. Jung, and T. W. Kim, Appl. Phys. Lett., 91, 122111 (2007)

276. Q. Lin, D. Liaw, E. Y. Teo, C. Zhu, D. S. Chan, E. Kang, and K. Neoh, Polymer, 48, 5182 (2007).

277. a) T. W. Kim, Y. Yang, F. Li, and W. L. Kwan, NPG Asia Materials, 4, e18, (2012).

278. N. G. Portney, A. A. Martinez-Morales, and M. Ozkan, ACS Nano, 2, 191 (2008)

279. W. L. Leong, N. Mathews, S. Mhaisalkar, Y. M. Lam, T. P. Chen, and P. S. Lee, J. Mater. Chem., 19, 7354 (2009).

280. B. Cho, S. Song, Y. Ji, T. Kim, and T. Lee, Adv. Funct. Mater, 21, 2806 (2011)

281. T. W. Kim, H. Choi, S. H. Oh, G. Wang, D. Y. Kim, H. Hwang, and T. O. Lee, Adv. Mater., 21, 2497 (2009). 
282. E. Y. H. Teo, C. Zhang, S. L. Lim, E. Kang, D. S. H. Chan, and C. Zhu, C. IEEE Elec. Dev. Lett., 30, 487 (2009).

283. H. Kim, W. Cho, D. U. Lee, S. P. Kim, and E. K. Kim, Appl. Phys. Lett., 91, 043513 (2007).

284. J. H. Kim, K. H. Baek, C. K. Kim, Y. B. Kim, and C. S. Yoon, Appl. Phys. Lett., 90, 123118 (2007).

285. C. Wu, F. Li, T. Guo, B. Qu, Z. Chen, and Q. Gong, Jpn. J. Appl. Phys., 50, 030204 (2011).

286. S. Stankovich, D. A. Dikin, G. H. B. Dommett, K. M. Kohlhaas, E. J. Zimney, E. A. Stach, R. D. Piner, S. T. Nguyen, and R. S. Ruoff, Nature, 442, 282 (2006).

287. M. Vilkman, K. Solehmainen, A. Laiho, H. G. O. Sandberg, and O. Ikkala, Org. Electron., 10, 1478 (2009).

288. S. Kim and J. Lee, Nano Lett., 10, 2884 (2010).

289. S. Moller, C. Perlov, W. Jackson, C. Taussig, and S. R. Forrest, Nature, 426, 166 (2003).

290. Q. Lai, Z. Li, L. Zhang, X. Li, W. F. Stickle, Z. Zhu, Z. Gu, T. I. Kamins, R. S. Williams, and Y. Chen, Nano Lett., 8, 876 (2008).

291. D. Son, J. Kim, D. Park, W. K. Choi, F. Li, J. H. Ham, and T. W. Kim, Nanotechnology, 19, 055204 (2008).

292. A. C. Arias, J. D. MacKenzie, I. McCulloch, J. Rivnay, and A. Salleo, Chem. Rev, 110, 3 (2010).

293. A. N. Sokolov, B. C. K. Tee, C. J. Bettinger, J. B. H. Tok, and Z. Bao, Acc. Chem. Res., 45, 361 (2011).

294. T. Sekitani and T. Someya, Adv. Mater, 22, 2228 (2010).

295. Y. Guo, G. Yu, and Y. Liu, Adv. Mater., 22, 4427 (2010).

296. C.-A. Di, F. Zhang, and D. Zhu, Adv. Mater, 25, 313 (2013).

297. Q.-D. Ling, D.-J. Liaw, C. Zhu, S.-H. Chan, E.-T. Kang, and K.-G. Neoh, Prog. Polym. Sci., 33, 917 (2008).
298. B. M. Dhar, R. Özgün, T. Dawidczyk, A. Andreou, and H. E. Katz, Mater. Sci. Eng., $R, 72,49$ (2011).

299. P. Heremans, G. H. Gelinck, R. Müller, K.-J. Baeg, D.-Y. Kim, and Y.-Y. Noh, Chem. Mater, 23, 341 (2010).

300. W. L. Leong, N. Mathews, B. Tan, S. Vaidyanathan, F. Dotz, and S. J. Mhaisalkar, J. Mater. Chem., 21, 5203 (2011).

301. J.-S. Lee, J. Mater. Chem., 21, 14097 (2011).

302. H.-C. Chang, C.-L. Liu, and W.-C. Chen, ACS Appl. Mater. Interfaces, 5, 13180 (2013).

303. S. Shah, M. I. Shiblee, S. H. Mir, L. A. Nagahara, P. K. Sekhar, M. Kawakami, H. Furukawa, and A. Khosla, Microsyst. Technol., (2017).

304. S. Shah, M. D. N. I. Shiblee, J. M. H. Rahman, S. Basher, S. H. Mir, M. Kawakami, H. Furukawa, and A. Khosla, (2018).

305. S. H. Mir and B. Ochiai, Adv. Mater. Interfaces, 4, 1601198 (2017).

306. W. Honda, S. Harada, T. Arie, S. Akita, and K. Takei, Adv. Funct. Mater., 24, 299 (2014).

307. R. A. Potyrailo, A. Burns, C. Surman, D. J. Lee, and E. McGinniss, Analyst, 137, 2777 (2012).

308. A. Pantelopoulos and N. G. Bourbakis, IEEE Trans. Syst. Man, Cybern. Part C Applications Rev., 40, 1 (2010).

309. A. M. Gaikwad, D. A. Steingart, T. N. Nga, D. E. Schwartz, and G. L. Whiting, Appl. Phys. Lett., 102, 233302 (2013).

310. M. Gong, Q. Liu, R. Gou, D. Ewing, M. Casper, A. Stramel, A. Elliot, and J. Z. Wu, ACS Appl. Mater. Interfaces, 9, 27801 (2017).

311. J. Li, J. Wu, S. Shao, Y. Deng, B. Meng, Z. Xie, Y. Geng, L. Wang, and F. Zhang, ACS Appl. Mater. Interfaces, 6, 8237 (2014).

312. H. Koga, T. Saito, T. Kitaoka, M. Nogi, K. Suganuma, and A. Isogai, Biomacromolecules, 14, 1160 (2013). 